\title{
Block-Copolymer Assisted Fabrication of Anisotropic Plasmonic Nanostructures
}

Calbi J. Gunder

Missouri State University, Gunder1@live.missouristate.edu

As with any intellectual project, the content and views expressed in this thesis may be considered objectionable by some readers. However, this student-scholar's work has been judged to have academic value by the student's thesis committee members trained in the discipline. The content and views expressed in this thesis are those of the student-scholar and are not endorsed by Missouri State University, its Graduate College, or its employees.

\section{Follow this and additional works at: https://bearworks.missouristate.edu/theses}

Part of the Atomic, Molecular and Optical Physics Commons, and the Polymer Chemistry

\section{Commons}

\section{Recommended Citation}

Gunder, Calbi J., "Block-Copolymer Assisted Fabrication of Anisotropic Plasmonic Nanostructures" (2018). MSU Graduate Theses. 3260.

https://bearworks.missouristate.edu/theses/3260

This article or document was made available through BearWorks, the institutional repository of Missouri State University. The work contained in it may be protected by copyright and require permission of the copyright holder for reuse or redistribution.

For more information, please contact BearWorks@library.missouristate.edu. 


\title{
BLOCK-COPOLYMER ASSISTED FABRICATION OF ANISOTROPIC PLASMONIC NANOSTRUCTURES
}

\author{
A Master's Thesis \\ Presented to \\ The Graduate College of \\ Missouri State University
}

\author{
In Partial Fulfillment \\ Of the Requirements for the Degree \\ Master of Science, Materials Science
}

\section{By}

Calbi Gunder

May 2018 


\section{Copyright 2018 by Calbi Gunder}




\title{
BLOCK-COPOLYMER ASSISTED FABRICATION OF ANISOTROPIC
}

\section{PLASMONIC NANOSTRUCTURES}

Department of Physics, Astronomy and Materials Science

Missouri State University, May 2018

Master of Science

Calbi Gunder

\begin{abstract}
The anisotropic nanostructures of noble metals are of great interest for plasmonic applications due to the possibility of tuning the localized surface plasmon resonance (LSPR) across the UV-VIS-NIR without sacrificing the linewidth as well as to achieve larger local field enhancement. Here, we report a simple and promising fabrication method of anisotropic gold nanostructures film using polystyrene-b-2vinylpyridine (PSb-P2VP) block copolymers (BCP) as a template. In this approach, PS-b-P2VP spherical micelles were first synthesized as a template followed by selective deposition of $\mathrm{Au}$ precursor inside $\mathrm{P} 2 \mathrm{VP}$ core of the micelles using ethanol solution of Au salt.

Subsequently, heat treatment of the precursor deposited BCP films followed by removal of the BCP template produced anisotropic gold nanostructures of various shapes, such as octahedron, icosahedron, tetrahedron, and triangular prism. A temperature- and timedependent annealing of the fabricated nanostructures led to the formation of clusters at higher temperatures. Furthermore, measurement of ensemble extinction spectra of the anisotropic Au nanoparticle films showed two broad distinct LSPR peaks; one in the visible range $(\sim 660 \mathrm{~nm})$, and the other in the NIR range $(\sim 875 \mathrm{~nm})$. The electrodynamic simulation showed that octahedron and icosahedron nanoparticles are responsible for the LSPR response in the visible; whereas the triangular shapes are responsible for the LSPR response in the NIR. Our work is expected to open up a new direction of synthesis of anisotropic nanostructures of noble metals that can be utilized to tune the LSPR response across the UV-VIS-NIR range using a simple BCP template-based method.
\end{abstract}

KEYWORDS: anisotropic, plasmonic, synthesis, spectra, nanoparticles

This abstract is approved as to form and content

Robert A. Mayanovic, $\mathrm{PhD}$

Chairperson, Advisory Committee

Missouri State University 


\title{
BLOCK-COPOLYMER ASSISTED FABRICATION OF ANISOTROPIC PLASMONIC NANOSTRUCTURES
}

\author{
By \\ Calbi Gunder

\begin{abstract}
A Master's Thesis
Submitted to the Graduate College

Of Missouri State University

In Partial Fulfillment of the Requirements

For the Degree of Master of Science, Materials Science
\end{abstract}

May 2018

Approved:

Robert A. Mayanovic, $\mathrm{PhD}$

Ridwan Sakidja, $\mathrm{PhD}$

Kartik Ghosh, PhD

Julie Masterson, PhD: Dean, Graduate College

In the interest of academic freedom and the principle of free speech, approval of this thesis indicates the format is acceptable and meets the academic criteria for the discipline as determined by the faculty that constitute the thesis committee. The content and views expressed in this thesis are those of the studentscholar and are not endorsed by Missouri State University, its Graduate College, or its employees. 


\section{ACKNOWLEDGEMENTS}

I would like to start with thanking my current advisor, Dr. Robert Mayanovic for being so understanding and helpful during and through the transition into his research group. He has been so supportive and helpful during this entire endeavor and honestly a student could not ask for a better advisor. To this end, I would also like to thank Dr. Mahua Biswas for allowing me to conduct research with her during her stay here at Missouri State University. This enabled me to learn a great deal about how the scientific community engages in research and has helped me grow as a researcher.

I would also like to put out a special thanks to Dr. Kartik Ghosh and Dr. Ridwan Sakidja for all the additional assistance that they provided to me. I am very grateful for all the comments, remarks and engagement in my academic and research success during my time at Missouri State University.

This would not be complete without thanking all the graduate students that helped me through this endeavor along with a special thanks to Krishna Pandey and separately to Rishi Patel for all of the assistance he had provided.

I dedicate this thesis to my mother, father and to all the freethinkers of the world. 


\section{TABLE OF CONTENTS}

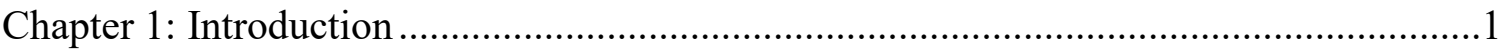

Fabrication and Thermal effects on Anisotropic Plasmonic Nanostructures............3

Chapter 2: Block-copolymer assisted fabrication of anisotropic plasmonic

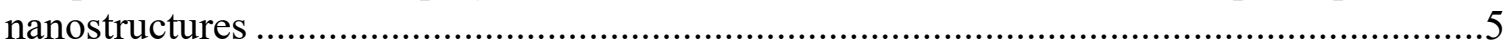

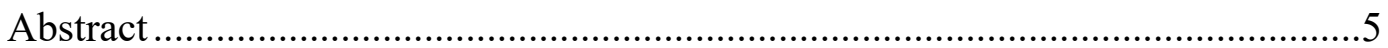

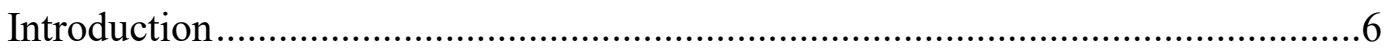

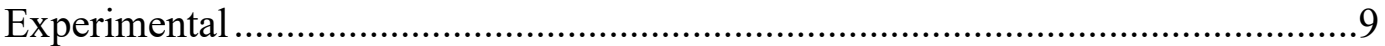

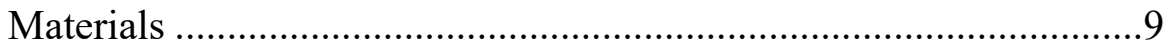

Block copolymer spherical micelles deposition ................................ 9

Fabrication of Au Nanoparticles ......................................................

Characterizations.................................................................... 10

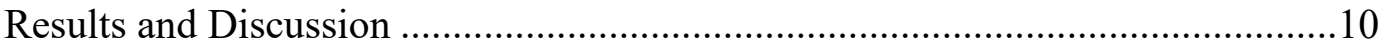

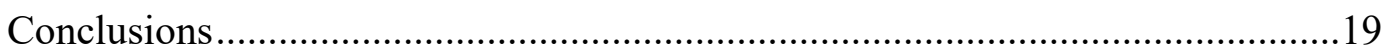

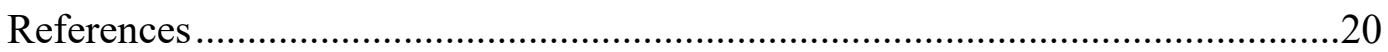

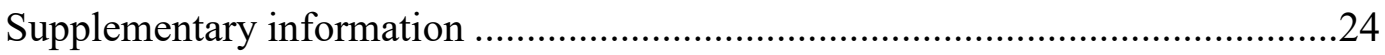

Chapter 3: Analytical effects of annealing time and temperature on a PS-b-P2VP blockcopolymer template for the fabrication of anisotropic nanoparticles ...............................26

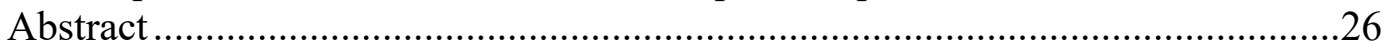

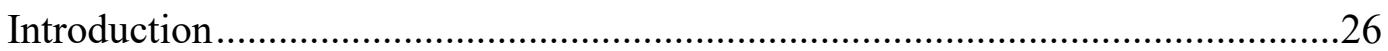

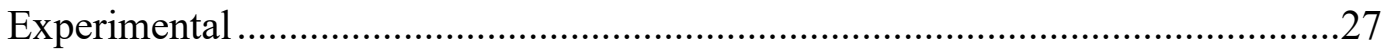

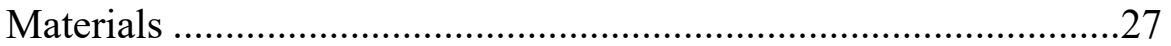

Block copolymer spherical micelles deposition ..............................28

Fabrication of Au Nanoparticles .....................................................28

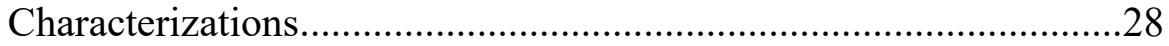

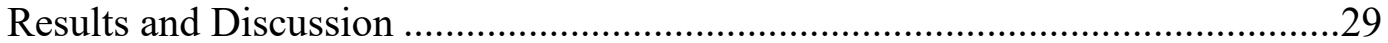

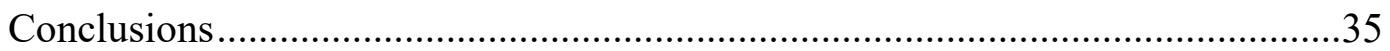

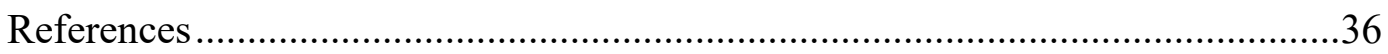

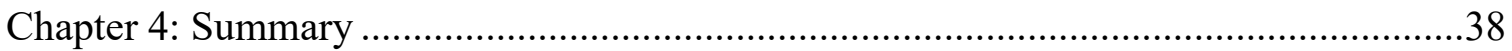

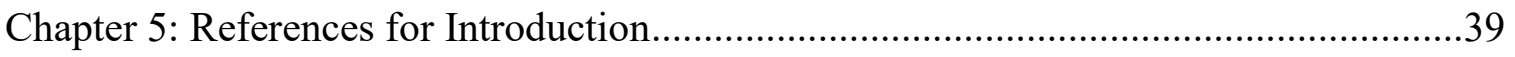




\section{LIST OF TABLES}

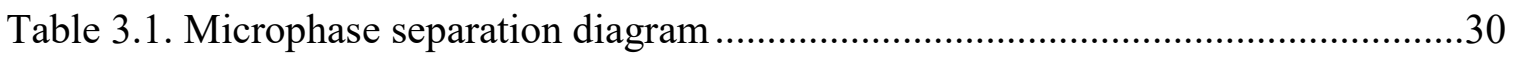




\section{LIST OF FIGURES}

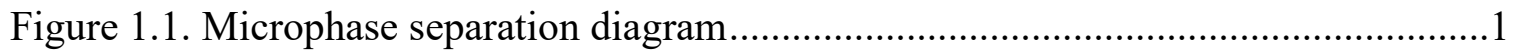

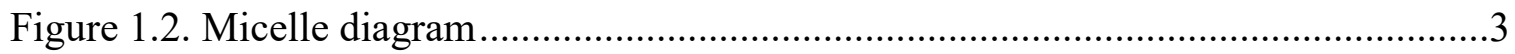

Figure 2.1. SEM images of each step to achieve anisotropic particle growth ..................12

Figure 2.2. SEM images of individual particles and histograms of both measured average

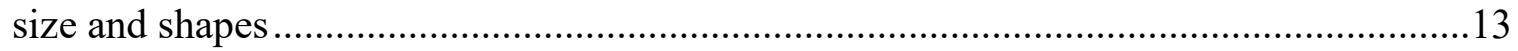

Figure 2.3. SEM of cluster formation ................................................................ 15

Figure 2.4. Measures ensemble extinctions of particles .............................................16

Figure 2.S1. High magnification SEM images of Au anisotropic nanoparticles..............24

Figure 2.S2. SEM images of Au anisotropic nanoparticles annealing in air ...................24

Figure 2.S3. SEM comparison of both air and nitrogen annealed samples .....................25

Figure 3.1. Mean particle size and total number of particles plotted against annealing time

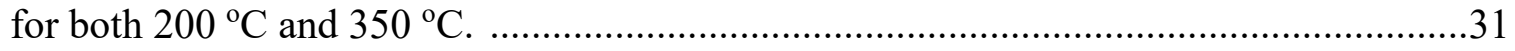

Figure 3.2. Histogram showing the change in mean particle size with varied temperature

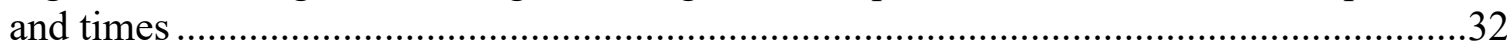

Figure 3.3. SEM of Au particulates on the substrates surface .....................................34

Figure 3.4. SEM images of $200{ }^{\circ} \mathrm{C}$ and $350{ }^{\circ} \mathrm{C}$ for $.5 \mathrm{hr}$, $2 \mathrm{hrs}$ and $8 \mathrm{hrs}$ of annealing.......34 


\section{INTRODUCTION}

Block copolymers (BCPs) have generated a lot of interest over the last several years for their ability to be used in nano-patterning. They can form a variety of microdomains including spherical, cylindrical, lamellar and gyroid. The formation of these microdomains are dependent on the volume fraction of components within the bulk. This can be seen in Figure 1.1 after the phase separation of these different block components has occurred [1].

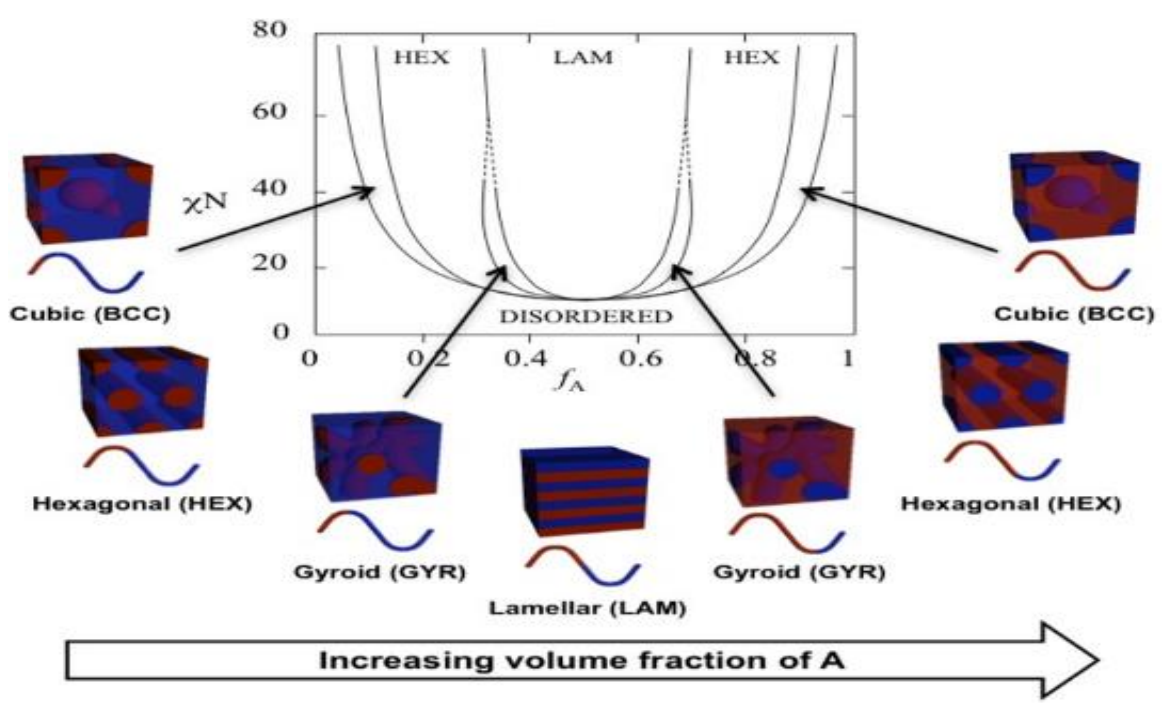

Figure 1.1: Microphase separation of BCPs and formation of different microdomains [2].

Phase separation of the BCP blocks can be influenced with additional parameters such as the film preparation method [3-4], film thickness [5-6] and interfacial interactions [7-8] which can directly affect the morphology. BCPs can be used as templates to fabricate various inorganic nanostructured materials such as spherical nanoparticles, nanotubes, nanodisks, nanowires, nanorings, and nanodots [9-11]. The size and shape of 
these inorganic nanostructures can be tuned by changing the BCP domain size. There are many applications that depend on the ability to tune these specific properties, some of which include chemical sensors, catalysis, information storage, electronics, optoelectronics, and photonics [9-14].

Currently there are several techniques for fabricating inorganic nanostructures which include photolithography, electron beam lithography and capillary lithography [1416]. These methods have been very useful but are limited by several factors. For example, conventional lithography is limited by low throughput due to the number of steps required to generate a particular nanostructure and by its high cost [18]. Often, these different lithography techniques can create locally ordered arrays in small areas but struggle with patterning over larger regions due to the difficulty involved in ordering colloid particles in a monolayer [19].

Block-copolymer self-assembly has shown itself to be a simple, flexible and powerful method that is capable of addressing several problems with existing fabrication techniques [20]. Block-copolymers allow the ability to control both the size and shape of microdomains over large areas while also proving to be a low-cost method for developing scaffolds for the fabrication of well-ordered inorganic nanostructures [20-22]. This procedure of inorganic nanostructure fabrication is usually termed as BCP lithography. Among different morphologies of BCP, spherical micelles have captured significant attention for the formation of inorganic nanoparticles of uniform shapes. These types of nanoparticles are of interest for plasmonic, photonics and biomedical applications [23, 24]. BCP fabrication of spherical nanoparticles usually takes the form of a micelle formation. A micelle forms by the separation of both blocks in a diblock-copolymer chain 
through their hydrophobic and hydrophilic nature by which one block will form the interior of the sphere and the other its surface as seen in Figure 1.2. Blocks can often be reversed by selecting a proper solvent to make the interior of micelles of the hydrophilic portion; this is termed as an inverse micelle morphology [25]. The fabrication of an inverse micelle morphology is usually used in cases by which the hydrophilic block is the interactive segment for the inorganic material deposition.

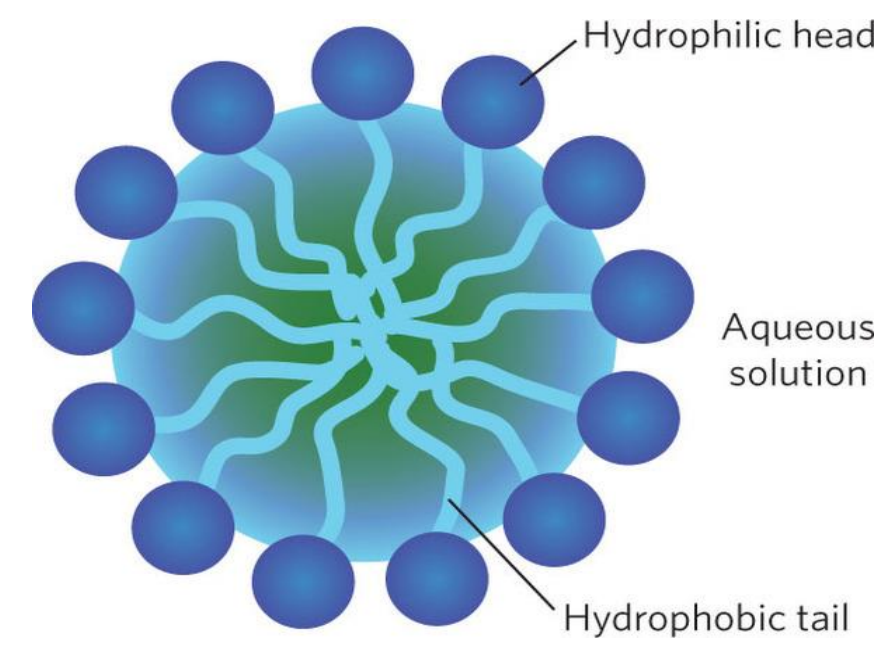

Figure 1.2 A schematic of a spherical micelle by separation of hydrophobic vs hydrophilic ends of diblock-copolymer chains in a solvent [26].

\section{Fabrication and Thermal effects on Anisotropic Plasmoic Nanostrucures}

The patterning of a micelle mophology can be used to great effect in materials research. With the addition of both thermodynamic and kinetic aspects we believe that the growth and nucleation of crystalline nanoparticles can be done within blockcopolymer micelles.

Chapter 2 of this thesis will go over the fabrication of anisotropic plasmonic nanostructures along with their localized surface plasmon resonance extinictions. This work has been submitted in Nanotechnology and presently under review. In Chapter 3 we 
take a more in depth look at the analytical effects of both annealing temperature and time on the fabrication of anisotropic nanoparticles. The results presented in Chapter 3 are presently is in preparation for journal submittion. 


\title{
CHAPTER 2: BLOCK-COPOLYMER ASSISTED FABRICATION OF ANISOTROPIC PLASMONIC NANOSTRUCTURES
}

\begin{abstract}
The anisotropic nanostructures of noble metals are of great interest for plasmonic applications due to the possibility of tuning the localized surface plasmon resonance (LSPR) across the UV-VIS-NIR without sacrificing the linewidth as well as to achieve larger local field enhancement. Here, we report a simple and promising fabrication method of anisotropic gold nanostructures film using polystyrene-b-2vinylpyridine (PSb-P2VP) block copolymers (BCP) as a template. In this approach, PS-b-P2VP spherical micelles were first synthesized as a template followed by selective deposition of Au precursor inside P2VP core of the micelles using ethanol solution of Au salt.

Subsequently, heat treatment of the precursor deposited BCP films followed by removal of the $\mathrm{BCP}$ template produced anisotropic gold nanostructures of various shapes, such as octahedron, icosahedron, tetrahedron, triangles, and triangular prism. A temperature and time dependent annealing of the fabricated nanostructures led to the formation of clusters at higher temperature. Furthermore, measurement of ensemble extinction spectra of the anisotropic Au nanoparticle films showed two broad distinct LSPR peaks; one in the visible range $(\sim 660 \mathrm{~nm})$, and the other in the NIR range $(\sim 875$ $\mathrm{nm})$. The electrodynamic simulation showed that octahedron and icosahedron nanoparticles are responsible for the LSPR response in the visible; whereas the triangular shapes are responsible for the LSPR response in the NIR. Our work is expected to open up a new direction of synthesis of anisotropic nanostructures of noble metals that can be
\end{abstract}


utilized to tune the LSPR response across the UV-VIS-NIR range using a simple BCP template-based method.

\section{Introduction}

Plasmonic excitations in nanoparticles provide a means for manipulating lightmatter interactions beyond the diffraction limit. This property is being developed into applications such as miniaturized optical [1] and electronic [2] devices, surface enhanced Raman scattering and localized surface plasmon resonance based chemical and biological sensing [3-4], and medical diagnostics and therapeutics [5-6]. Moreover, anisotropic features in nonspherical nanoparticles make them ideal candidates for enhanced chemical [7-9], catalytic [9-10], and local field related applications $[9,11]$.

The plasmonic excitations in nanoparticles in the UV-VIS-NIR spectral range are mainly determined by oscillation of conduction electrons that give rise to so-called localized surface plasmon resonance (LSPRs) observable in their extinction, i.e. absorption and scattering, spectra [12-13]. It is well-known that the optical properties of metal nanostructures (e.g., peak position, linewidth) are strongly sensitive to the size, shape, and dielectric properties of the surrounding medium [14-15]. An uneven distribution of electromagnetic fields around anisotropic metal nanoparticles can give rise to shape dependent LSPR spectra. In the case of spherical nanoparticles, the LSPR spectra can be tuned by changing the size of the nanoparticles; however, the dipolar response becomes significantly broadened due to radiation damping [16]. On the other hand, the LSPR can be elegantly tuned across the UV-VIS-NIR without sacrificing the linewidth of the resonance through changing the nanoparticle geometry [17-18]. 
Moreover, it has been shown that the local field enhancement factor depends on the particle eccentricity, and the local field enhancement at the tip of a spheroid is larger than the one created by a resonant sphere [19-21]. For example, it has been shown that gold nanorods have higher local field enhancement factors than nanoshells and nanospheres [22].

The ability of anisotropic metal nanoparticles, in particular gold (Au) nanoparticles to tune LSPR across the UV-VIS-NIR without sacrificing the linewidth, and large local field enhancements have been shown to be useful for biomolecular manipulation, labeling, and detection [4, 23] as well as other applications [24-26]. In this regard, synthesis of metal nanostructures with controlled dimension and shapes, adaptability with different deposition methods, substrate flexibility and large area adaptability to achieve greater sensitivity and specificity is critical. In last several years, anisotropic Au nanostructures have been synthesized using various synthesis strategies, such as by reducing Au precursors using various strategies like seed mediated synthesis [27-29], polyol synthesis [30-32], photochemistry [33-34], electrochemical synthesis [35] and biochemistry [36-39]. Using these synthesis methods anisotropic Au nanostructures of different geometries (cubes [28, 35], triangle [38], prism [34], tetrahedra [40-41], octahedra [42], decahedra [43], icosahedra [44] and bipyramids [45]) were obtained.

Alternately, templated synthesis of nanostructures has some evident advantages over other methods such as controllable dimension and shapes, adaptability with different deposition methods, substrate flexibility and large area adaptability [46-47]. In this regard, block copolymer (BCP) templated lithography of various inorganic materials have received significant attraction due to its ability to be self-assembled into a variety of 
different nanostructure patterns along with the ease of removing the polymeric template [48-49]. The BCP templated method has been previously used to fabricate anisotropic metal nanoparticles [42, 50-51]. However, in these methods, the metal precursor loaded BCP micelles were vigorously stirred [52] or annealed in air [42] to produce anisotropic metal nanoparticles (octahedral, tetrahedral and icosahedral) with LSPR response only in the visible range.

In this work, we have used a simple $\mathrm{BCP}$ templated method to fabricate $\mathrm{Au}$ nanoparticles of different shapes with LSPR response in the visible (VIS) - near infrared (NIR) range. More specifically, we have used a disorderly aggregated polystyrene-blockpoly(2vinylpyridine) (PS-b-P2VP) BCP spherical micelles as template, and heat treated the $\mathrm{Au}$ precursor tetrachroloauric acid $\left(\mathrm{HAuCl}_{4}\right)$ loaded disordered $\mathrm{BCP}$ micelles in inert atmosphere to fabricate Au nanoparticle films of various shapes (octahedron, icosahedron, triangles, and triangular prism) at a relatively low temperature. Moreover, our results also show that one can change the spacing between individual nanoparticles by varying the annealing time and temperature to produce nanoparticle clusters. It is believed that the disorderly aggregated Au salt loaded micelles produce anisotropic Au nanoparticles while going through rapid crystallization during heat treatment in inert atmosphere; subsequently, at higher temperature, the Au particles assemble in the coalesced P2VP polymer-melt to produce nanoparticle clusters in the inert atmosphere. Measurement of extinction spectra of the anisotropic Au nanoparticle films showed distinct peaks in the visible $(\sim 660 \mathrm{~nm})$ and near infra-red $(\sim 875 \mathrm{~nm})$ range. The electrodynamic simulation performed by Finite Difference Time Domain (FDTD) 
method showed that the visible peak arises due to octahedron and icosahedron $\mathrm{Au}$ nanoparticles, whereas the near infra-red peak arises due to triangles and triangular prism.

\section{Experimental}

Materials: Polystyrene-block-poly(2-vinlypyridine) (PS-b-P2VP) diblock

copolymer $\left(\mathrm{M}_{\mathrm{n}}{ }^{\mathrm{PS}}: 440 \mathrm{~kg} \mathrm{~mol}^{-1}, \mathrm{M}_{\mathrm{n}}^{\mathrm{P}}{ }^{\mathrm{VP}}: 353 \mathrm{~kg} \mathrm{~mol}^{-1}, \mathrm{M}_{\mathrm{w}} / \mathrm{M}_{\mathrm{n}}: 1.19\right)$ used for making BCP spherical micelles were purchased from Polymer Sources Inc. O-xylene solvent was used in making the solution of PS-b-P2VP copolymer. Tetrachloroauric acid $\left(\mathrm{HAuCl}_{4}\right)$ and ethanol was used for Au deposition. All chemicals mentioned above and the cleaning solution of $\mathrm{Si}$ (Hydrogen Peroxide $\left(\mathrm{H}_{2} \mathrm{O}_{2}\right)$ and Ammonium Hydroxide $\left(\mathrm{NH}_{4} \mathrm{OH}\right)$ ) were purchased from Sigma Aldrich.

Block co-polymer spherical micelles deposition: The BCP films were deposited on Si substrates with native oxide for all the experiments in this paper. The Si substrates were cleaned using $\mathrm{H}_{2} \mathrm{O}_{2}, \mathrm{NH}_{4} \mathrm{OH}$ and Distilled water, in the ratio of $1: 1: 5$ at $65^{\circ} \mathrm{C}$ for 2.5 hrs to eliminate residual organic traces from the Si surface. Predetermined amount of PSb-P2VP BCP powder was dissolved in o-xylene solvent at room temperature to make a $5 \mathrm{wt} \% \mathrm{BCP}$ solution. This solution is allowed to stir for 24 hours before being spin-coated onto the cleaned Si substrates.

Fabrication of Au Nanoparticles: The PS-b-P2VP micelles deposited samples were dipped at room temperature in an Au precursor solution of $0.3 \mathrm{wt} \% \mathrm{HAuCl}_{4}$ in ethanol for 20 minutes. This Au salt is expected to bind only with the pyridine groups of P2VP polymer in the PS-b-P2VP BCPs [18, 28]. After gold deposition the samples were rinsed with deionized water multiple times in order to remove excess Au salts. Annealing 
of these $\mathrm{Au}$ precursor infiltrated $\mathrm{BCP}$ micelle samples were done using a hot plate inside a nitrogen filled glove box and in air (depending on the experiment) at different temperatures. In some of the experiments, the samples were etched using oxygen plasma (March plasma etcher) for removing all the polymers from the samples to obtain $\mathrm{Au}$ nanoparticle films on Si.

Characterizations: The $\mathrm{BCP}$ nanostructures and the Au nanostructures were imaged using a Field Emission Scanning Electron Microscope (FESEM) by FEI Quanta 200 FEG instrument. The extinction spectra were measured by using a bright-field optical microscopy set-up. The set-up used a bright-field condenser (Olympus, NA $=0.5)$ and a $60 \times$ water immersion objective (NA $\leq 1.2$, Olympus UPLSAPO). An incoherent (tungsten- halogen) white light sources were used to illuminate the nanoparticle films and measure the spectra over the $450-1000 \mathrm{~nm}$ wavelength range. The extinction spectra were recorded by an CCD array detector (Andor, Newton) connected to a $303 \mathrm{~mm}$ CzernyTurner imaging spectrometer (Andor, Shamrock 303i) coupled to the side port of the microscope via a home-built achromatic $4 f$ relay system.

\section{Results and Discussion}

Fig. 1 (a) shows the PS-b-P2VP micelles deposited on Si without any treatment. PS-b-P2VP was dissolved in PS selective solvent o-xylene which forms inverse micelles with P2VP spherical core and PS corona. The size distribution of the spherical micelles is in the range of $\sim 60-80 \mathrm{~nm}$ as observed from Fig. 1 (a). This PS-b-P2VP micelles dipped in the solution of Au precursor $\mathrm{HAuCl}_{4}$ and ethanol serves two purposes: $(i)$ selectively swallow the P2VP cores using ethanol which is a selective solvent of P2VP [53] and (ii) 
infiltrate $\mathrm{HAuCl}_{4}$ inside the swollen and aggregated $\mathrm{P} 2 \mathrm{VP}$ cores where $\mathrm{HAuCl}_{4}$ interacts with the pyridine group of P2VP. The micelle cores aggregate disorderly and some also migrate to the surface while soaking in $\mathrm{HAuCl}_{4}$ ethanol solution as seen from Fig. 1 (b). Subsequently, a heat treatment of $\mathrm{HAuCl}_{4}$ loaded disorderly aggregated PS-b-P2VP micelles in inert atmosphere promotes the formation of various geometrical shapes of $\mathrm{Au}$ nanoparticles at relatively low temperatures as shown in Figure 2.1 (d), which otherwise form disorderly aggregated Au spherical nanoparticles after polymer etching as shown in Figure 2.1 (c).

Figure 2.2 shows the Au nanoparticles of different shapes that are formed from $\mathrm{HAuCl}_{4}$ loaded PS-b-P2VP micelle film due to the treatment at different temperatures and times in inert atmosphere. We used three different temperatures $100{ }^{\circ} \mathrm{C}, 200{ }^{\circ} \mathrm{C}$ and $350{ }^{\circ} \mathrm{C}$ to treat the $\mathrm{HAuCl}_{4}$ loaded BCPs. From Figure 2.2 (a) and (b), one can see that at $100{ }^{\circ} \mathrm{C}$, the polymer removed Au nanoparticle films show a resemblance of films formed without any heat treatment as shown in Figure 2.1 (b). Figure 2.2 (c) and (d) show the $200{ }^{\circ} \mathrm{C}$ treated samples for $2 \mathrm{hrs}$ and $4 \mathrm{hrs}$, respectively. At these experimental conditions, we observe the formation of anisotropic Au nanoparticles with different shapes. The samples heat treated at $350{ }^{\circ} \mathrm{C}$ for $2 \mathrm{hrs}$ and $4 \mathrm{hrs}$ also exhibit anisotropic $\mathrm{Au}$ nanoparticles with different shapes as shown in Figure 2.2 (e) and (f), respectively. Note that for samples heat treated at $350{ }^{\circ} \mathrm{C}$ for $2 \mathrm{hrs}$ and $4 \mathrm{hrs}$, the separations amongst the nanoparticles are somewhat reduced leading to the formation of nanoparticle clusters (discussed in more details in subsequent sections). 


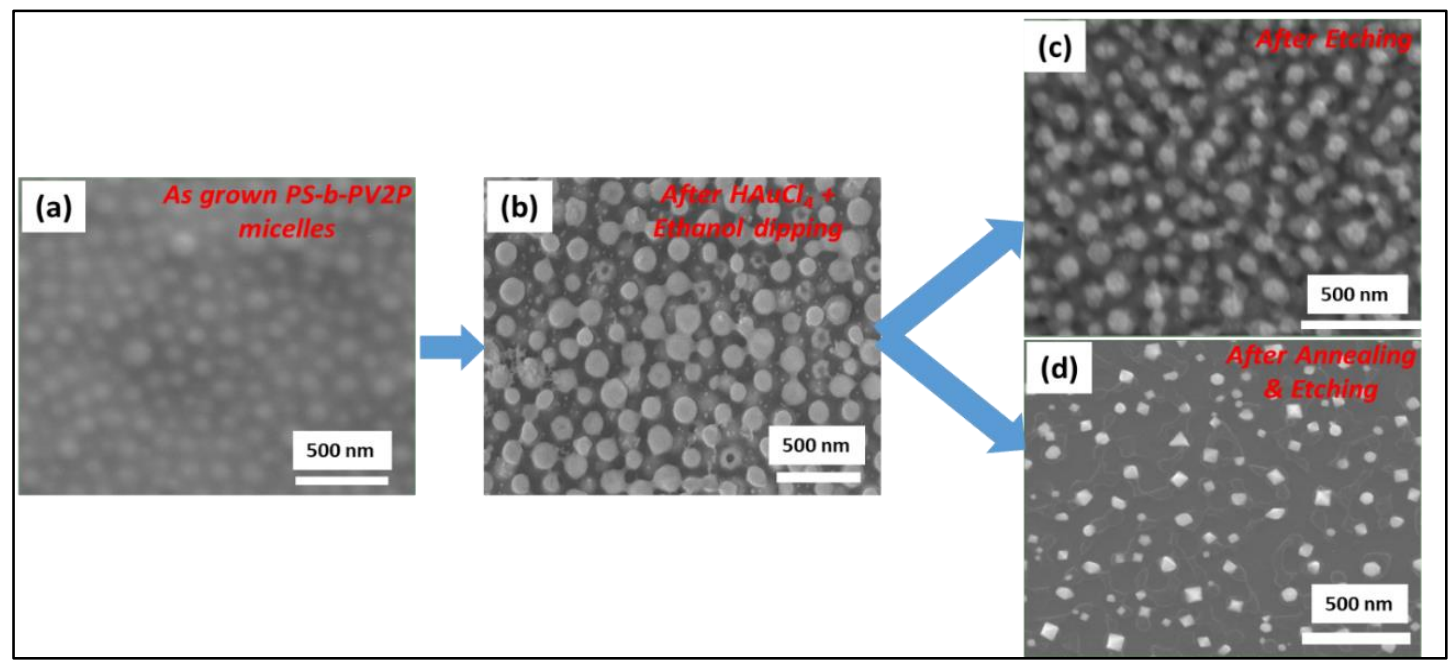

Figure 2.1: SEM images of (a) as-grown PS-b-P2VP spherical micelle film, (b) PS-b-P2VP micelle film shown in (a) dipped in $\mathrm{HAuCl}_{4}$ and ethanol solution and formed disorderly aggregated micelles, (c) disorderly aggregated Au spherical nanoparticle film after polymer etching the sample shown in (b), and (d) $\mathrm{Au}$ anisotropic nanoparticle film after annealing (at $200{ }^{\circ} \mathrm{C}$ ) and polymer etching the sample shown in (b).

It has been shown previously that disordered aggregation of micelles as a template can lead to the formation of metal anisotropic nanostructures in the presence of proper reducing agents [52]; whereas an ordered micelles template upon heat treatment at a relatively high temperature can lead to the formation of metal anisotropic structures as well at relatively high temperature [42]. The mechanism of nucleation and growth of anisotropic Au nanoparticles formation is a complicated process with possibility of both kinetically and thermodynamically controlled growth; moreover, the presence of a spherical capping materials which is polymer in this case makes it a rather complex process. In our work, we show that the disorderly aggregation of Au salt loaded micelles when subject to rapid crystallization upon heating can form anisotropic nanostructures of definitive shapes even at a relatively low temperature of $200{ }^{\circ} \mathrm{C}$ to relieve the stress. We believe that the growth and nucleation of these particles have both kinetic as well as 
thermodynamic aspects that allow the Au nanoparticles to transform into three dimensional anisotropic shapes of higher surface to volume ratios which consequently leads to more energy per atom. The kinetic aspect is the aggregation and displacement of P2VP micellar core loaded with Au precursor due to the use of P2VP selective solvent ethanol; this played an important role in the formation of different shapes of Au particles which would have been otherwise spherical in shape due to the protective spherical BCP micelles. In the thermodynamic aspect, these randomly aggregated particles took the shape of different geometrical structures after heat treatment. What this shows is that these anisotropic shapes are the most thermodynamically stable forms of Au crystals while minimizing the surface energy of the particles to reach equilibrium [52, 54-55].

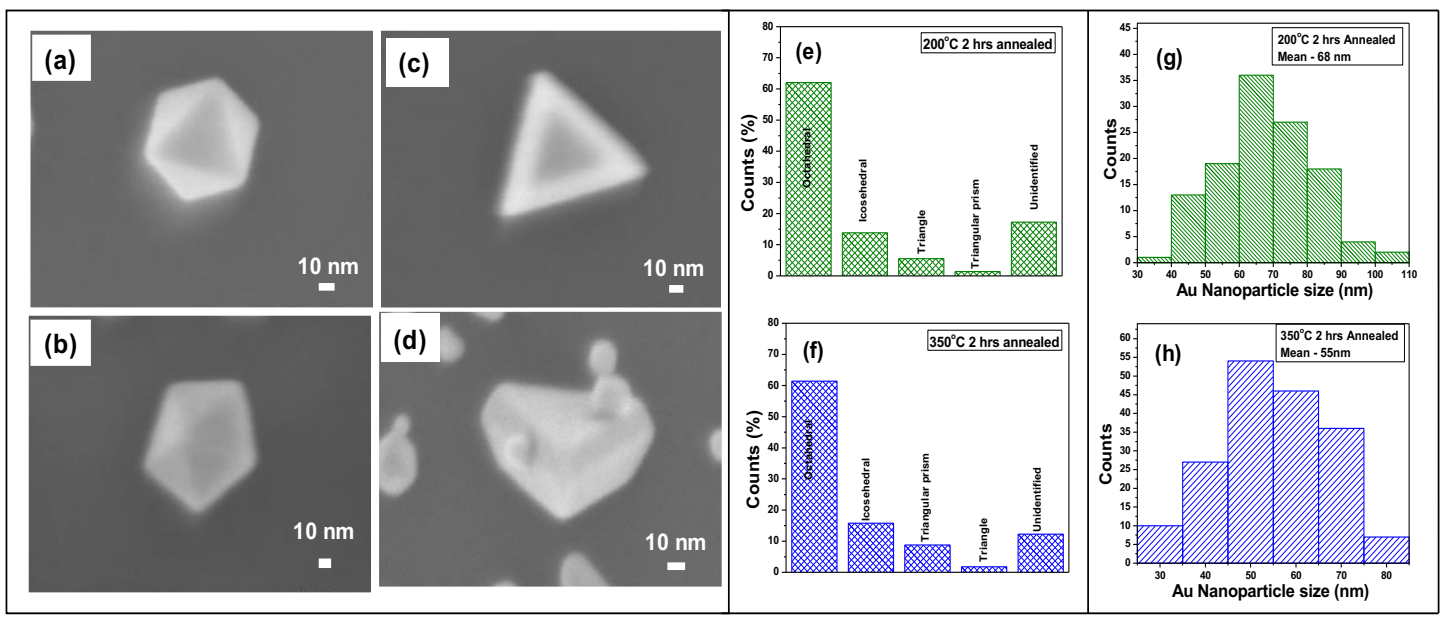

Figure 2.2: (a-d) SEM images of different shapes of Au nanoparticles formed due to annealing at $200{ }^{\circ} \mathrm{C}$ and $350{ }^{\circ} \mathrm{C}$ for $2 \mathrm{hrs}$ and $4 \mathrm{hrs}$. The anisotropic shapes are Octahedral (a), icosahedral (b), triangular (c) and beveled triangular prism (d). (e) \& (f) show the histograms showing the percentage of the different shape of particles formed at $200{ }^{\circ} \mathrm{C} \& 350{ }^{\circ} \mathrm{C}$, respectively. (g) \& (h) Histogram plots of the Au nanoparticle size calculated from the SEM images of Au nanoparticle films shown in Fig. 2 at $200{ }^{\circ} \mathrm{C}$ for $2 \mathrm{hrs}(\mathrm{g})$, and $350{ }^{\circ} \mathrm{C}$ for $2 \mathrm{hrs}(\mathrm{h})$. 
As mentioned earlier, by increasing annealing time and temperature the separation among nanoparticles are reduced. This led to the formation of nanoparticle clusters at 350 ${ }^{\circ} \mathrm{C}$ as shown in Figures 2.2 (e) and (f). To further elucidate that the clusters are indeed formed during annealing and not during the removal of polymers: SEM images were recorded directly after the annealing of Au loaded polymers but before the removal of the polymer. From the SEM images in Figure. 2.4 (a) and (b), the assembly of particles at $350{ }^{\circ} \mathrm{C}, 2 \mathrm{hrs}$ treated film and cluster formation for $350^{\circ} \mathrm{C}, 4 \mathrm{hrs}$ film is clearly visible even before the polymer removal.

The formation of a cluster can be attributed to the movement of the $\mathrm{Au}$ nanoparticles within the polymer matrix in the inert atmosphere. Note that in our experiment, the annealing temperature is higher than the glass transition temperatures of both PS and P2VP [56] $\left(\mathrm{T}_{\mathrm{g}} \sim 100{ }^{\circ} \mathrm{C}\right)$. At $\mathrm{T}>>\mathrm{Tg}$, the polymer chains are kinetically more active leading to the formation of polymer melts. At this point, the polymers maintain the molten form due to the presence of the inert atmosphere, which protects the molten polymers from oxidative etching that would otherwise occur in air. During the heating process groups of disordered P2VP micelles which are the host of $\mathrm{Au}$ nanoparticles coalesces lead to the formation of localized droplets of minority P2VP within the majority matrix of molten PS. The anisotropic Au particles seem to form closely packed clusters inside the coalesced P2VP regions as can be seen in Figure 2.4. The coalesced P2VP regions become more discrete and localized within PS domain as the applied heating energy increases. However, due to the random movement of the polymer chains; the separation amongst nanoparticles in clusters are also somewhat random. 


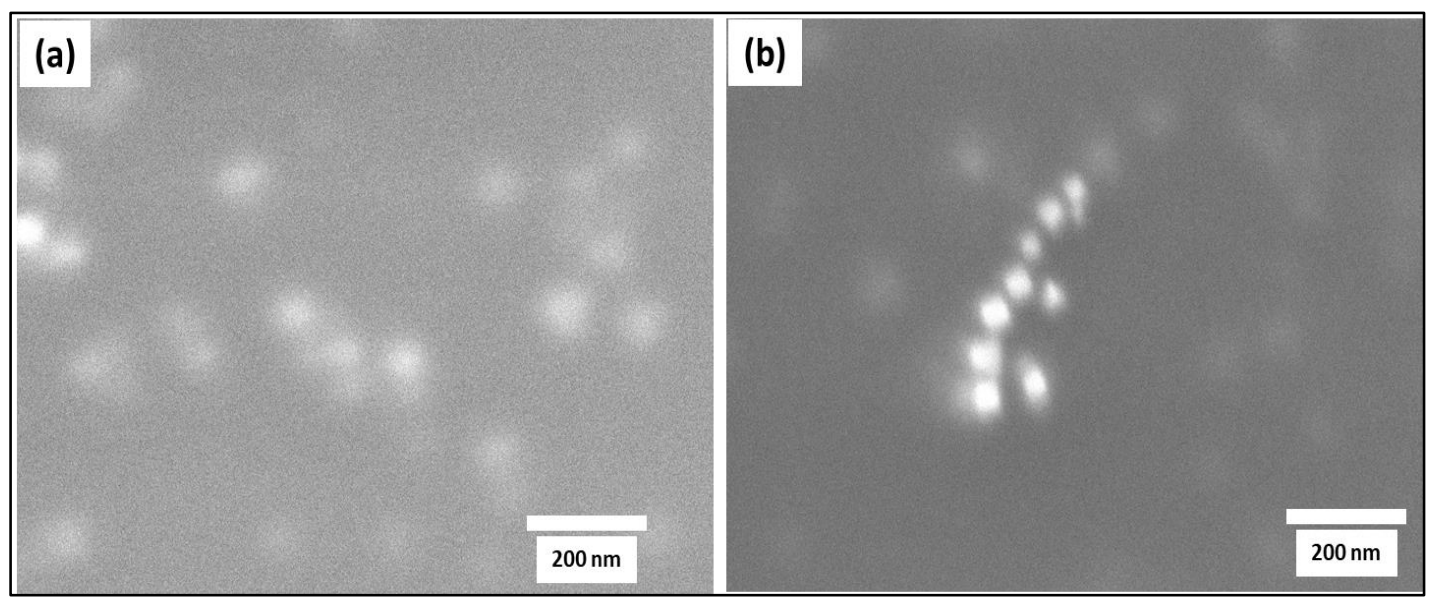

Figure 2.3: SEM images of Au nanoparticles in the polymer matrix after annealing, before removal of the polymers in inert atmosphere, at (a) $350{ }^{\circ} \mathrm{C}$ for $2 \mathrm{hrs}$ and (b) 350 ${ }^{\circ} \mathrm{C}$ for 4 hrs.

To verify this hypothesis of cluster formation, we have performed annealing experiments on the same Au precursor loaded PS-b-P2VP micelles in an air atmosphere. The SEM images of air annealed films at $200{ }^{\circ} \mathrm{C}$ for $2 \mathrm{hrs}, 200{ }^{\circ} \mathrm{C}$ for $4 \mathrm{hrs}, 350{ }^{\circ} \mathrm{C}$ for 2 hrs, and $350{ }^{\circ} \mathrm{C}$ for $4 \mathrm{hrs}$ are shown in Figure 2.S2 (a)-(d) and Figure 2.S3 (e)-(h) in SI, respectively. From the SEM images of air annealed samples; we observed $\mathrm{Au}$ nanoparticles of different geometrical shapes. This correlates well with $\mathrm{N}_{2}$ annealed films, but the distribution is very uniform for air annealing without any cluster formation at a higher temperature of $350^{\circ} \mathrm{C}$. This can be attributed to the well-known fact of evaporation of polymers during annealing in air at $350{ }^{\circ} \mathrm{C}$ due to oxidative etching. Our observation is in agreement with the results reported by Fenniri et. al. [42] during similar annealing experiment of $\mathrm{HAuCl}_{4}$ loaded BCPs in air. The distribution of the anisotropic Au particles in the films annealed at different temperatures and times in air and $\mathrm{N}_{2}$ environments are shown in the low magnification SEM images in Figure 2.S3 for comparison. 
It is well known that the optical, physical and chemical properties are different in different directions for an anisotropic metal structure compared to its isotropic counterpart due to the confinement of electrons and consequent changes in electronic energy levels [12]. As a result, the optical properties of anisotropic nanostructures deviate from their spherical counterpart. For example, anisotropic metal nanoparticles, such as rods, disks, and triangular prisms, the LSPRs are typically split into distinctive dipole and quadrupole plasmon modes [57-58]. Furthermore, for prolate spheroidal particles, the dipole resonance splits into two absorption bands, longitudinal and transverse modes [59] with the longitudinal resonance band shifting towards longer and increasing absorption cross-section as the aspect ratio of the spheroid increases [59-60].
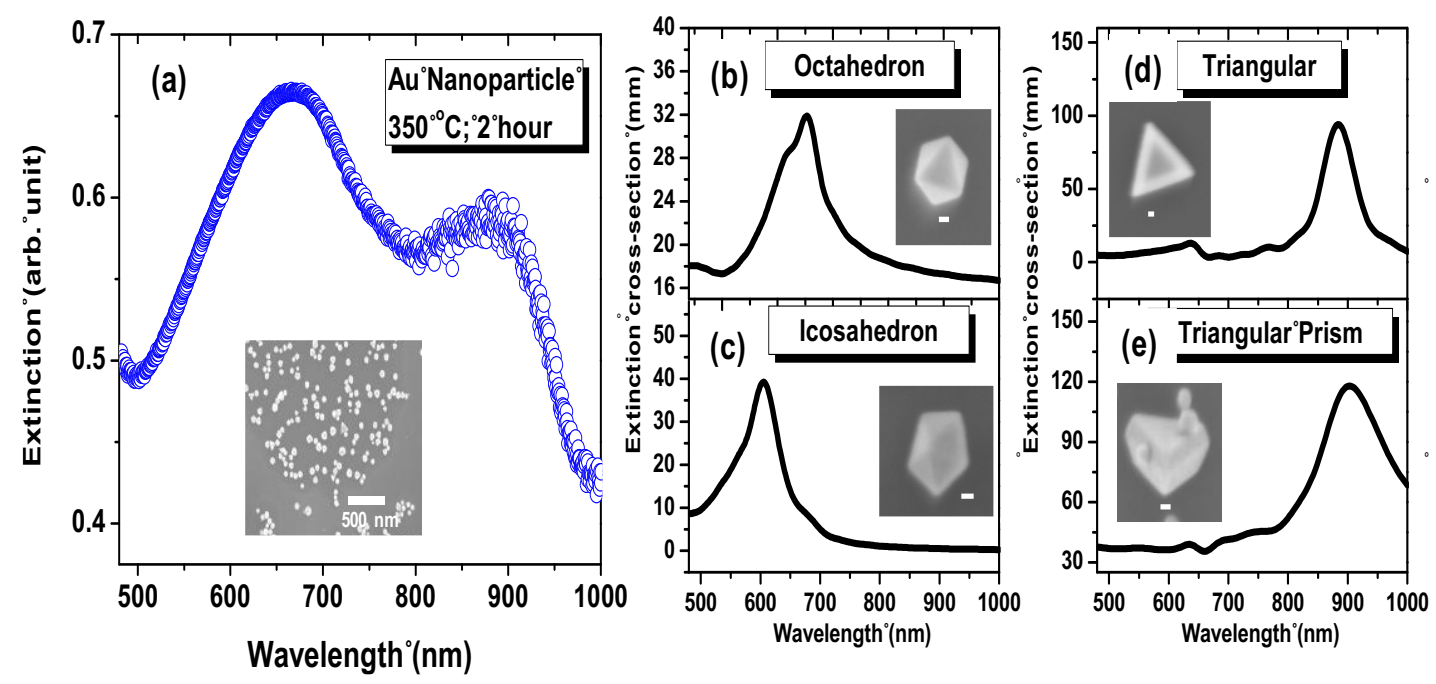

Figure 2.4: (a) Measured ensemble extinction spectra of Au nanoparticle film fabricated by annealing the sample at $350^{\circ} \mathrm{C}$ for 4 hours. (b) Calculated the extinction spectra of the individual octahedron, icosahedron, triangles, and triangular prism nanoparticles using FDTD method. The presence of a large number of heterogeneous anisotropic structures with the LSPR response in the visible and NIR range, and their associated orientation average response produce broad peaks in the visible and NIR range. 
To find out the collective LSPR of the fabricated anisotropic Au nanoparticle film, we have measured the ensemble averaged extinction spectra in the vis-NIR range as shown in Figure 2.4 (a) for the sample fabricated by $350^{\circ} \mathrm{C}$ annealing for 4 hours. The extinction spectra show two broad distinct peaks; one in the visible range (center $\sim 660$ $\mathrm{nm}, \mathrm{FWHM} \sim 200 \mathrm{~nm}$ ), and the other in the NIR range (center $\sim 875 \mathrm{~nm}, \mathrm{FWHM} \sim 80$ $\mathrm{nm})$. To find out the origin of these two peaks, we have calculated the extinction spectra of the individual octahedron, icosahedron, triangles, and triangular prism nanoparticles using FDTD method. As shown in Figure 2.4 (b-e), the extinction spectra of the octahedron and icosahedron nanoparticles show LSPR response in the visible range (center $\sim 600-660 \mathrm{~nm}$ ); whereas the extinction spectra of the triangular, and triangular prism nanoparticles are dominated by the LSPR response in the NIR range (center $\sim 900$ $\mathrm{nm}$ ) accompanied by very weak LSPR response in the in the visible range. Note that the peak positions are highly sensitive to the size parameters of the anisotropic nanoparticles (not shown here); and for the sake of consistency we have chosen the size parameters of the representative nanoparticles of Figure 2.3 (also shown in inset of Figure 2.4 (b-e)). Since the particle size is relatively small (average size $\sim 55-60 \mathrm{~nm}$ ) with a dimension much less than the wavelength of the light, all the conduction electrons are excited inphase with the incident excitation; hence the LSPR peaks that appear in the extinction spectra are due to the dipolar excitation. For the triangular, and triangular prism nanoparticles, the dominant peak in the NIR range can be attributed to the LSPR response along the long-axis, and the weaker peaks in the visible range can be attributed to the shorter axis [15]. Our calculated results are consistent with the morphology dependent LSPR spectra of polyhedral (cube, octahedra, cuboctahedra, icosahedra, decahedra) 
nanoparticles that the main LSPR peak position is blue-shifted as the number of faces increase or the nanoparticles become more symmetric as calculated by Noguez and coworkers for silver nanoparticles [17-18].

In addition to dependence on the heterogeneity of the shape and size, unlike nanosphere, the LSPR wavelength of the anisotropic nanoparticles depends on the orientation of the of the incident light relative to the particle. Hence, the ensemble average spectra represent a heterogeneity dependent as well as the orientation average response. In our experiment, due to of the presence of a large number of heterogeneous anisotropic structures with the LSPR response in the visible as well as NIR range, and their associated orientation average response, we observe broad peaks in the visible and NIR range. Nevertheless, our results show that LSPR wavelength can be tuned across the VIS-NIR resonance through changing the nanoparticle geometry. We are currently looking into the possibility of producing anisotropic nanoparticles with less heterogeneity in shape and size which correlate their optical properties with particle morphology.

\section{Conclusions}

We report a simple fabrication method of Au anisotropic nanoparticles using PSb-P2VP micellar template. The Au precursor loaded P2VP micelles disorderly aggregate and displaced with the use of P2VP selective solvent ethanol with the Au precursor which forms Au nanoparticles of various geometrical shapes namely octahedral, icosahedral, triangle and triangular prism after heat treatment at relatively low temperature. We show that by simply annealing an Au deposited BCP film with different times and temperatures can lead to the formation of clusters. Extinction spectroscopy of the anisotropic $\mathrm{Au}$ 
nanoparticle films showed two LSPR peaks in the visible range (center $\sim 650 \mathrm{~nm}$ ), and the other in the NIR range (center $\sim 875 \mathrm{~nm}$ ). The electrodynamic simulation showed that octahedron and icosahedron nanoparticles are responsible for the LSPR response in the visible range; whereas the triangular, and triangular prism are responsible for the LSPR response in the NIR range. This work will be attractive for the applications of anisotropic nanoparticles of noble metals that can be utilized to tune the LSPR response across the UV-VIS-NIR range without sacrificing the linewidth of the resonance. We are in the process of optimizing the presented $\mathrm{BCP}$ templated method for controlled synthesis of shapes and size distribution by controlling the micelle aggregation and heating process. 


\section{References}

[1] Schuller, J. A.; Barnard, E. S.; Cai, W.; Jun, Y. C.; White, J. S.; Brongersma, M. L., Plasmonics for extreme light concentration and manipulation. Nature Materials 2010, 9, 193.

[2] Ozbay, E., Plasmonics: Merging Photonics and Electronics at Nanoscale Dimensions. Science 2006, 311 (5758), 189-193.

[3] Shipway, A. N.; Katz, E.; Willner, I., Nanoparticle Arrays on Surfaces for Electronic, Optical, and Sensor Applications. ChemPhysChem 2000, 1 (1), 18-52.

[4] Anker, J. N.; Hall, W. P.; Lyandres, O.; Shah, N. C.; Zhao, J.; Van Duyne, R. P., Biosensing with plasmonic nanosensors. Nature Materials 2008, 7, 442.

[5] Haes, A. J.; Zou, S.; Zhao, J.; Schatz, G. C.; Van Duyne, R. P., Localized Surface Plasmon Resonance Spectroscopy near Molecular Resonances. Journal of the American Chemical Society 2006, 128 (33), 10905-10914.

[6] Lal, S.; Clare, S. E.; Halas, N. J., Nanoshell-Enabled Photothermal Cancer Therapy: Impending Clinical Impact. Accounts of Chemical Research 2008, 41 (12), 18421851.

[7] Jang, N. H.; Suh, J. S.; Moskovits, M., Photochemical Desorption of 4Vinylbenzoic Acid Adsorbed on Silver Colloid Surfaces. The Journal of Physical Chemistry B 1997, 101 (9), 1649-1654.

[8] Yin, Y.; Erdonmez, C.; Aloni, S.; Alivisatos, A. P., Faceting of Nanocrystals during Chemical Transformation: From Solid Silver Spheres to Hollow Gold Octahedra. Journal of the American Chemical Society 2006, 128 (39), 12671-12673.

[9] Sau, T. K.; Rogach, A. L.; Jäckel, F.; Klar, T. A.; Feldmann, J., Properties and Applications of Colloidal Nonspherical Noble Metal Nanoparticles. Advanced Materials 2010, 22 (16), 1805-1825.

[10] Tian, N.; Zhou, Z.-Y.; Sun, S.-G.; Ding, Y.; Wang, Z. L., Synthesis of Tetrahexahedral Platinum Nanocrystals with High-Index Facets and High ElectroOxidation Activity. Science 2007, 316 (5825), 732-735.

[11] Hao, F.; Nehl, C. L.; Hafner, J. H.; Nordlander, P., Plasmon Resonances of a Gold Nanostar. Nano Letters 2007, 7 (3), 729-732.

[12] Daniel, M.-C.; Astruc, D., Gold Nanoparticles: Assembly, Supramolecular Chemistry, Quantum-Size-Related Properties, and Applications toward Biology, Catalysis, and Nanotechnology. Chemical Reviews 2004, 104 (1), 293-346.

[13] Myroshnychenko, V.; Rodriguez-Fernandez, J.; Pastoriza-Santos, I.; Funston, A. M.; Novo, C.; Mulvaney, P.; Liz-Marzan, L. M.; Garcia de Abajo, F. J., Modelling the optical response of gold nanoparticles. Chemical Society Reviews 2008, 37 (9), 1792-1805.

[14] Kreibig, U.; Vollmer, M., Optical Properties of Metal Clusters. Springer: 1995.

[15] Kelly, K. L.; Coronado, E.; Zhao, L. L.; Schatz, G. C., The Optical Properties of Metal Nanoparticles: The Influence of Size, Shape, and Dielectric Environment. The Journal of Physical Chemistry B 2003, 107 (3), 668-677.

[16] Yguerabide, J.; Yguerabide, E. E., Light-Scattering Submicroscopic Particles as Highly Fluorescent Analogs and Their Use as Tracer Labels in Clinical and Biological Applications: I. Theory. Analytical Biochemistry 1998, 262 (2), 137156. 
[17] Noguez, C., Surface Plasmons on Metal Nanoparticles: The Influence of Shape and Physical Environment. The Journal of Physical Chemistry C 2007, 111 (10), 3806-3819.

[18] Sadeghi, H.; Dorranian, D., Influence of size and morphology on the optical properties of carbon nanostructures. Journal of Theoretical and Applied Physics 2016, 10 (1), 7-13.

[19] Zeman, E. J.; Schatz, G. C., An accurate electromagnetic theory study of surface enhancement factors for silver, gold, copper, lithium, sodium, aluminum, gallium, indium, zinc, and cadmium. The Journal of Physical Chemistry 1987, 91 (3), 634643.

[20] Wokaun, A.; Gordon, J. P.; Liao, P. F., Radiation Damping in Surface-Enhanced Raman Scattering. Physical Review Letters 1982, 48 (14), 957-960.

[21] Xu, H.; Aizpurua, J.; Käll, M.; Apell, P., Electromagnetic contributions to singlemolecule sensitivity in surface-enhanced Raman scattering. Physical Review E 2000, 62 (3), 4318-4324.

[22] Jain, P. K.; Lee, K. S.; El-Sayed, I. H.; El-Sayed, M. A., Calculated Absorption and Scattering Properties of Gold Nanoparticles of Different Size, Shape, and Composition: Applications in Biological Imaging and Biomedicine. The Journal of Physical Chemistry B 2006, 110 (14), 7238-7248.

[23] Sperling, R. A.; Rivera Gil, P.; Zhang, F.; Zanella, M.; Parak, W. J., Biological applications of gold nanoparticles. Chemical Society Reviews 2008, 37 (9), 18961908.

[24] Huang, X.; El-Sayed, I. H.; Qian, W.; El-Sayed, M. A., Cancer Cell Imaging and Photothermal Therapy in the Near-Infrared Region by Using Gold Nanorods. Journal of the American Chemical Society 2006, 128 (6), 2115-2120.

[25] Zijlstra, P.; Chon, J. W. M.; Gu, M., Five-dimensional optical recording mediated by surface plasmons in gold nanorods. Nature 2009, 459, 410.

[26] Pan, H.; Chen, W.; Feng, Y. P.; Ji, W.; Lin, J., Optical limiting properties of metal nanowires. Applied Physics Letters 2006, 88 (22), 223106.

[27] Millstone, J. E.; Métraux, G. S.; Mirkin, C. A., Controlling the Edge Length of Gold Nanoprisms via a Seed-Mediated Approach. Advanced Functional Materials 2006, $16(9), 1209-1214$.

[28] Sau, T. K.; Murphy, C. J., Room Temperature, High-Yield Synthesis of Multiple Shapes of Gold Nanoparticles in Aqueous Solution. Journal of the American Chemical Society 2004, 126 (28), 8648-8649.

[29] Fan, F.-R.; Liu, D.-Y.; Wu, Y.-F.; Duan, S.; Xie, Z.-X.; Jiang, Z.-Y.; Tian, Z.-Q., Epitaxial Growth of Heterogeneous Metal Nanocrystals: From Gold Nanooctahedra to Palladium and Silver Nanocubes. Journal of the American Chemical Society 2008, 130 (22), 6949-6951.

[30] Lu, X.; Rycenga, M.; Skrabalak, S. E.; Wiley, B.; Xia, Y., Chemical Synthesis of Novel Plasmonic Nanoparticles. Annual Review of Physical Chemistry 2009, 60 (1), 167-192.

[31] Im, S. H.; Lee, Y. T.; Wiley, B.; Xia, Y., Large-Scale Synthesis of Silver Nanocubes: The Role of $\mathrm{HCl}$ in Promoting Cube Perfection and Monodispersity. Angewandte Chemie International Edition 2005, 44 (14), 2154-2157. 
[32] Xiong, Y.; Siekkinen, A. R.; Wang, J.; Yin, Y.; Kim, M. J.; Xia, Y., Synthesis of silver nanoplates at high yields by slowing down the polyol reduction of silver nitrate with polyacrylamide. Journal of Materials Chemistry 2007, 17 (25), 26002602.

[33] Budd, P. M.; Elabas, E. S.; Ghanem, B. S.; Makhseed, S.; McKeown, N. B.; Msayib, K. J.; Tattershall, C. E.; Wang, D., Solution-Processed, Organophilic Membrane Derived from a Polymer of Intrinsic Microporosity. Advanced Materials 2004, 16 (5), 456-459.

[34] Rongchao, J.; Cao, Y. C.; Encai, H.; Métraux, G. S.; Schatz, G. C.; Mirkin, C. A., Controlling anisotropic nanoparticle growth through plasmon excitation. Nature 2003, 425 (6957), 487.

[35] Lin Chen, K.; Jung Huang, C.; Hsiang Chiu, P.; Her Wang, Y., Synthesis of the Gold Nanocubes by Electrochemical Method with Surfactant Solution and Acetone Solvent Addition. 2010; Vol. 434-435, p 434-437.

[36] Xie, J.; Lee, J. Y.; Wang, D. I. C.; Ting, Y. P., Silver Nanoplates: From Biological to Biomimetic Synthesis. ACS Nano 2007, 1 (5), 429-439.

[37] Klaus, T.; Joerger, R.; Olsson, E.; Granqvist, C.-G., Silver-based crystalline nanoparticles, microbially fabricated. Proceedings of the National Academy of Sciences 1999, 96 (24), 13611-13614.

[38] Shankar, S. S.; Rai, A.; Ankamwar, B.; Singh, A.; Ahmad, A.; Sastry, M., Biological synthesis of triangular gold nanoprisms. Nature Materials 2004, 3, 482.

[39] Liu, B.; Xie, J.; Lee, J. Y.; Ting, Y. P.; Chen, J. P., Optimization of High-Yield Biological Synthesis of Single-Crystalline Gold Nanoplates. The Journal of Physical Chemistry B 2005, 109 (32), 15256-15263.

[40] Kim, F.; Connor, S.; Song, H.; Kuykendall, T.; Yang, P., Platonic Gold Nanocrystals. Angewandte Chemie 2004, 116 (28), 3759-3763.

[41] Kim, F.; Connor, S.; Song, H.; Kuykendall, T.; Yang, P., Platonic Gold Nanocrystals. Angewandte Chemie International Edition 2004, 43 (28), 36733677.

[42] Zhang, J.; Gao, Y.; Alvarez-Puebla, R. A.; Buriak, J. M.; Fenniri, H., Synthesis and SERS Properties of Nanocrystalline Gold Octahedra Generated from Thermal Decomposition of HAuCl4 in Block Copolymers. Advanced Materials 2006, 18 (24), 3233-3237.

[43] Sánchez-Iglesias, A.; Pastoriza-Santos, I.; Pérez-Juste, J.; Rodríguez-González, B.; García de Abajo, F. J.; Liz-Marzán, L. M., Synthesis and Optical Properties of Gold Nanodecahedra with Size Control. Advanced Materials 2006, 18 (19), 25292534.

[44] Xu, J.; Li, S.; Weng, J.; Wang, X.; Zhou, Z.; Yang, K.; Liu, M.; Chen, X.; Cui, Q.; Cao, M.; Zhang, Q., Hydrothermal Syntheses of Gold Nanocrystals: From Icosahedral to Its Truncated Form. Advanced Functional Materials 2008, 18 (2), 277-284.

[45] Kou, X.; Ni, W.; Tsung, C.-K.; Chan, K.; Lin, H.-Q.; Stucky, G. D.; Wang, J., Growth of Gold Bipyramids with Improved Yield and Their Curvature-Directed Oxidation. Small 2007, 3 (12), 2103-2113. 
[46] Martin, C. R., Nanomaterials: A Membrane-Based Synthetic Approach. Science 1994, 266 (5193), 1961-1966.

[47] Meng, G.; Han, F.; Zhao, X.; Chen, B.; Yang, D.; Liu, J.; Xu, Q.; Kong, M.; Zhu, X.; Jung, Y. J.; Yang, Y.; Chu, Z.; Ye, M.; Kar, S.; Vajtai, R.; Ajayan, P. M., A General Synthetic Approach to Interconnected Nanowire/Nanotube and Nanotube/Nanowire/Nanotube Heterojunctions with Branched Topology. Angewandte Chemie International Edition 2009, 48 (39), 7166-7170.

[48] Tseng, Y.-C.; Darling, S. B., Block Copolymer Nanostructures for Technology. Polymers 2010, 2 (4), 470.

[49] Nunns, A.; Gwyther, J.; Manners, I., Inorganic block copolymer lithography. Polymer 2013, 54 (4), 1269-1284.

[50] Goy-Lopez, S.; Juarez, J.; Cambon, A.; Botana, J.; Pereiro, M.; Baldomir, D.; Taboada, P.; Mosquera, V., Block copolymer-regulated synthesis of gold nanocrystals with sharp tips and edges. Journal of Materials Chemistry 2010, 20 (32), 6808-6814.

[51] Goy-López, S.; Castro, E.; Taboada, P.; Mosquera, V., Block Copolymer-Mediated Synthesis of Size-Tunable Gold Nanospheres and Nanoplates. Langmuir 2008, 24 (22), 13186-13196.

[52] Selvan, S. T.; Hayakawa, T.; Nogami, M.; Möller, M., Block Copolymer Mediated Synthesis of Gold Quantum Dots and Novel Gold-Polypyrrole Nanocomposites. The Journal of Physical Chemistry B 1999, 103 (35), 7441-7448.

[53] Mei, S.; Jin, Z., Mesoporous Block-Copolymer Nanospheres Prepared by Selective Swelling. Small 2013, 9 (2), 322-329.

[54] Ahmadi, T. S.; Wang, Z. L.; Henglein, A.; El-Sayed, M. A., "Cubic" Colloidal Platinum Nanoparticles. Chemistry of Materials 1996, 8 (6), 1161-1163.

[55] Wales, D. J.; Kirkland, A. I.; Jefferson, D. A., Structure and growth of colloidal metal particles. The Journal of Chemical Physics 1989, 91 (1), 603-611.

[56] Efremov, M. Y.; Olson, E. A.; Zhang, M.; Allen, L. H., Glass transition of thin films of poly(2-vinyl pyridine) and poly(methyl methacrylate): nanocalorimetry measurements. Thermochimica Acta 2003, 403 (1), 37-41.

[57] Nelayah, J.; Kociak, M.; Stéphan, O.; García de Abajo, F. J.; Tencé, M.; Henrard, L.; Taverna, D.; Pastoriza-Santos, I.; Liz-Marzán, L. M.; Colliex, C., Mapping surface plasmons on a single metallic nanoparticle. Nature Physics 2007, 3, 348.

[58] Bohren, C.; Huffmann, D., Absorption and Scattering of Light by Small Particles. John-Wiley: New York, 1983.

[59] Blatchford, C. G.; Campbell, J. R.; Creighton, J. A., Plasma resonance - enhanced raman scattering by absorbates on gold colloids: The effects of aggregation. Surface Science 1982, 120 (2), 435-455.

[60] Link, S.; El-Sayed, M. A., Spectral Properties and Relaxation Dynamics of Surface Plasmon Electronic Oscillations in Gold and Silver Nanodots and Nanorods. The Journal of Physical Chemistry B 1999, 103 (40), 8410-8426. 


\section{Supplementary Information}

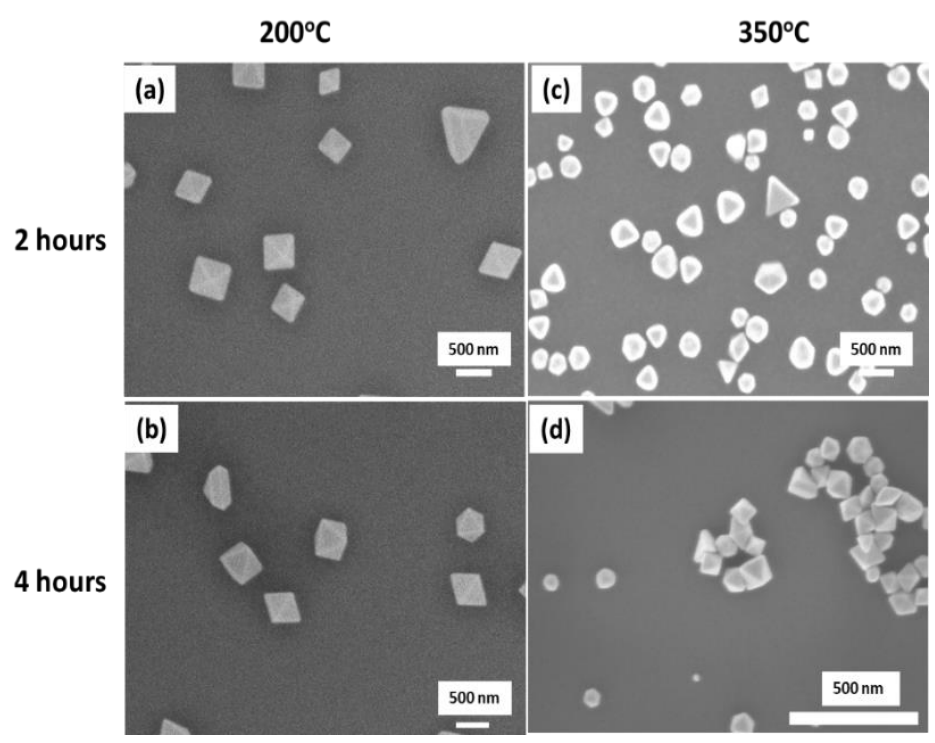

Figure 2.S1: High magnification SEM images of Au anisotropic nanoparticles after polymer etching, at (a) $200{ }^{\circ} \mathrm{C}$ for $2 \mathrm{hrs}$, (b) $200{ }^{\circ} \mathrm{C}$ for $4 \mathrm{hrs}$, (c) $350{ }^{\circ} \mathrm{C}$ for 2 hrs and (d) $350{ }^{\circ} \mathrm{C}$ for $4 \mathrm{hrs}$.

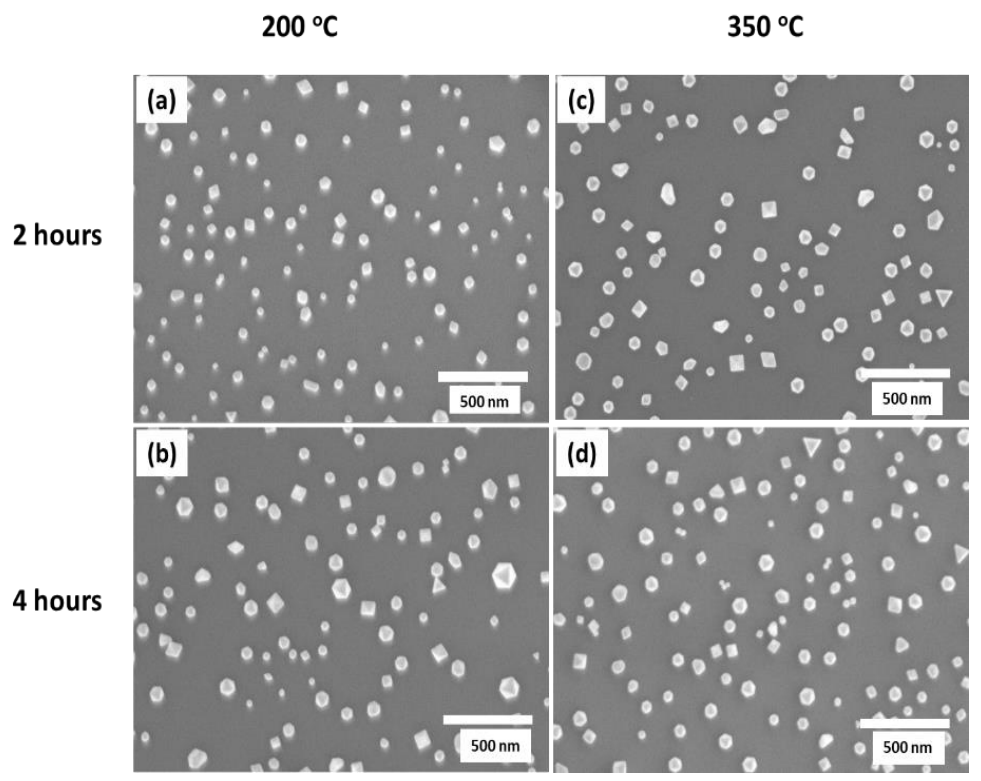

Figure 2.S2: SEM images of $\mathrm{Au}$ anisotropic nanoparticle films after polymer etching where $\mathrm{HAuCl}_{4}$ loaded PS-b-P2VP micelles annealed in air instead of $\mathrm{N}_{2}$, at (a) $200{ }^{\circ} \mathrm{C}$ for $2 \mathrm{hrs}$, (b) $200{ }^{\circ} \mathrm{C}$ for $4 \mathrm{hrs}$, (c) $350{ }^{\circ} \mathrm{C}$ for $2 \mathrm{hrs}$ and (d) $350{ }^{\circ} \mathrm{C}$ for $4 \mathrm{hrs}$. 


\section{Nitrogen \\ Annealed}
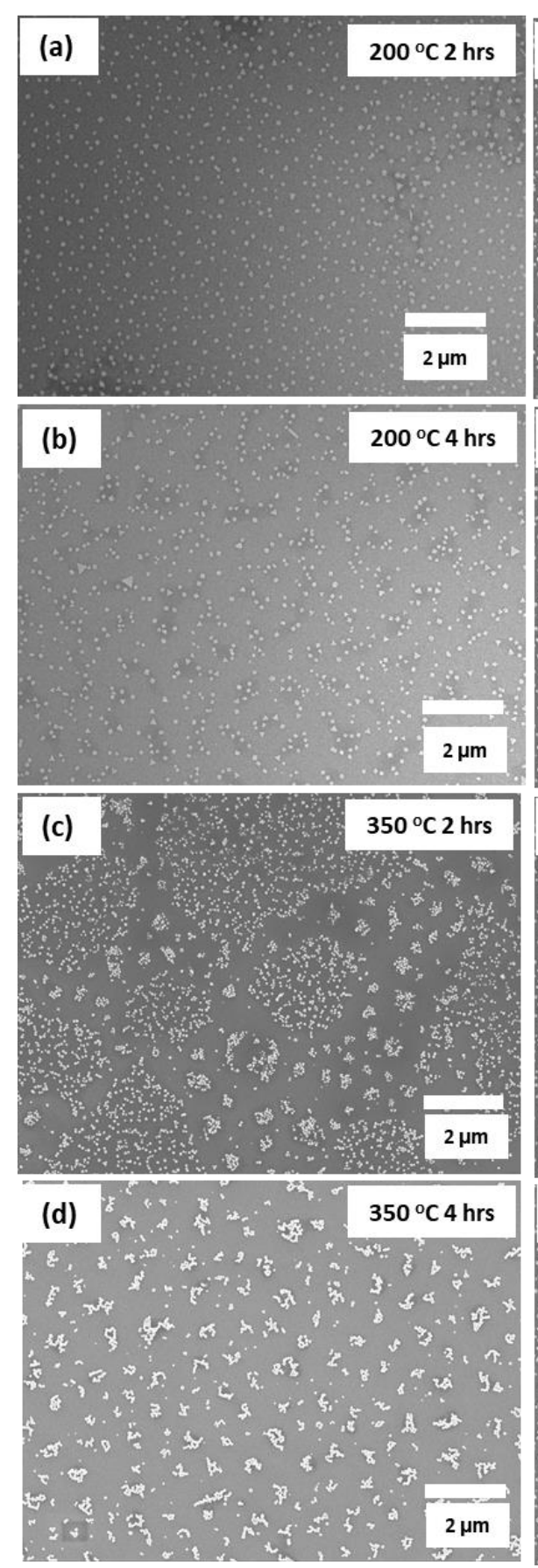

Air

Annealed
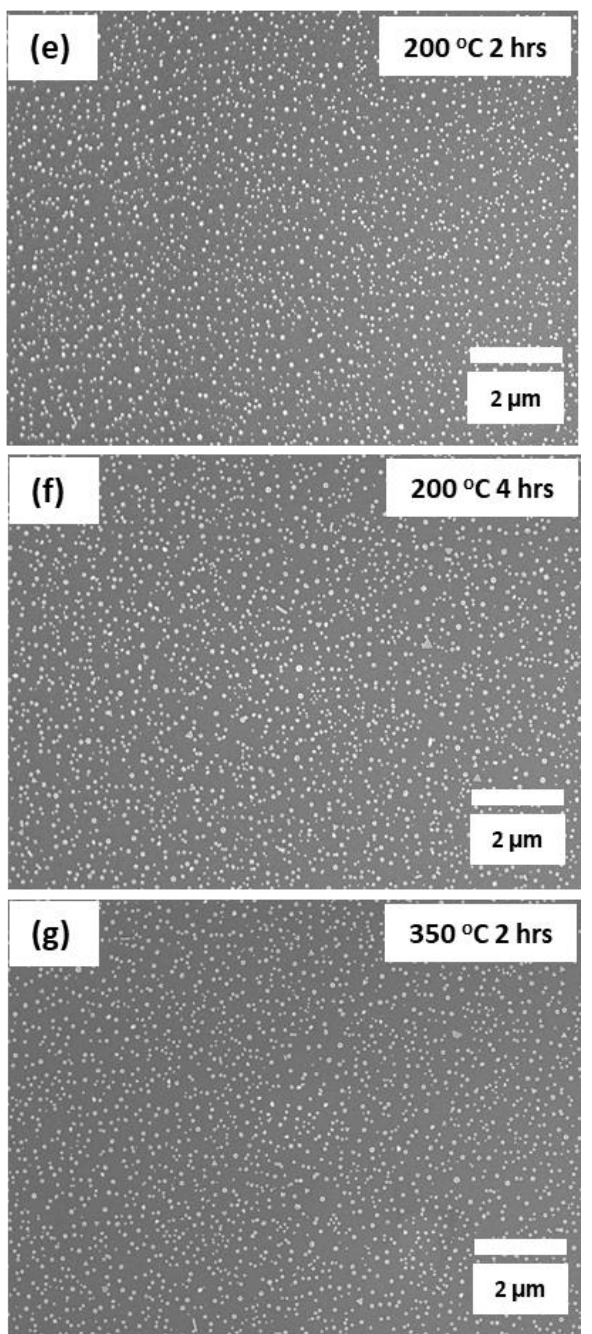

(h)

Figure 2.S3: SEM images to compare Au anisotropic nanoparticle films after polymer etching where $\mathrm{HAuCl}_{4}$ loaded PS-b-P2VP micelles annealed at different temperatures and times in $\mathrm{N}_{2}(\mathrm{a})-(\mathrm{d})$ and (e)-(h) in air. 


\title{
CHAPTER 3: SYNTHESIS EFFECTS OF ANNEALING TIME AND \\ TEMPERATURE ON THE FABRICATION OF ANISOTROPIC NANOPARTICLES USING A PS-b-P2VP BLOCK-COPOLYMER TEMPLATE
}

\begin{abstract}
The ability to control and understand the growth of crystalline structures has long been of interest in the scientific community and even further with the age of technology in terms of patterning and synthesis of nanostructures for a variety of different applications. This study has been designed to perform an analysis of both the size and morphological dependence of anisotropic nanostructures in relation to annealing temperature and time of a loaded Au salt micelles film of PS-b-P2VP in order to show how these two parameters can be manipulated to fine tune the size of anisotropic nanostructures on a substrate.
\end{abstract}

\section{Introduction}

With the ever-increasing demand to control both plasmonic and photonic properties of materials more so is the need to fabricate materials or nanostructures that are capable of achieving these desired properties. One such method that can be used to achieve this is block-copolymer (BCP) lithography. This patterning method has generated a lot of interest for the variety of patterning templates that can achieved and for its ability of direct self-assembly [1-3]. For instance, a broad range of homogeneous nanostructures have been synthesized by self-assembly suing BCPs, such as horizontal cylinders, spherical, etc. [4-7] over extensive surfaces without much difficulty. This method makes 
it more feasible to pattern large surfaces quickly in comparison to other lithography techniques such as photolithography, electron beam lithography, colloidal lithography and capillary lithography [8-11]. Great progress has been made toward the selective fabrication of noble metals into a variety of different shapes including rods [12], prisms [13], wires [14], cubes [15] by the use of block-copolymer templates; each with their own applicable purposes. For example, it has been shown that gold nanorods have a higher local field enhancement factor in relation to nanoshells or nanospheres [16]. This characteristic has been shown to be useful for labeling, biomolecular manipulation and detection [17-18] including other applications [19-21]. More specifically anisotropic nanoparticles can be useful for catalytic [22-23], enhanced chemical [23-25] and local field applications [22-26]. It has been shown that the shape and size of metal nanostructures affect optical properties in respect to their peak positions and even linewidth [27-28]. In this regard, it is important to investigate additional methods of manipulation such as the effects of annealing temperature and time; in order to determine how this can affect the patterning of anisotropic nanoparticles through the use of blockcopolymer templating.

\section{Experimental}

Materials. Polystyrene-block-poly(2-vinlypyridine) (PS-b-P2VP) diblock copolymer $\left(\mathrm{M}_{\mathrm{n}}{ }^{\mathrm{PS}}: 440 \mathrm{~kg} \mathrm{~mol}^{-1}, \mathrm{M}_{\mathrm{n}}{ }^{\mathrm{P} V \mathrm{VP}}: 353 \mathrm{~kg} \mathrm{~mol}^{-1}, \mathrm{M}_{\mathrm{w}} / \mathrm{M}_{\mathrm{n}}\right.$ : 1.19$)$ were used for making BCP spherical micelles and was purchased from Polymer Sources Inc. O-xylene solvent was used in making both solutions of PS-b-P2VP copolymers. Tetrachloroauric acid $\left(\mathrm{HAuCl}_{4}\right)$ and ethanol was used for Au deposition. All chemicals mentioned above 
and the cleaning solution of $\mathrm{Si}$ (Hydrogen Peroxide $\left(\mathrm{H}_{2} \mathrm{O}_{2}\right)$ and Ammonium Hydroxide $\left.\left(\mathrm{NH}_{4} \mathrm{OH}\right)\right)$ were purchased from Sigma Aldrich.

Block co-polymer spherical micelles deposition. The BCP films were deposited on Si substrates with native oxide for all the experiments in this paper. The Si substrates were cleaned using $\mathrm{H}_{2} \mathrm{O}_{2}, \mathrm{NH}_{4} \mathrm{OH}$ and Distilled water, in the ratio of $1: 1: 5$ at $65^{\circ} \mathrm{C}$ for 2.5 hrs to eliminate residual organic traces from the Si surface. O-xylene solvent was used to dissolve a predetermined amount of PS $(440,000)$-b-P2VP $(353,000)$ BCP powder at room temperature to make a solution of $5 \mathrm{wt} \% \mathrm{BCP}$ solution. The dissolved solution was stirred for 24 hours before being spin-coated onto cleaned Si substrates.

Fabrication of Au Nanoparticles. PS-b-P2VP micelles deposited samples were dipped at room temperature in an $\mathrm{Au}$ precursor solution of $0.3 \mathrm{wt} \% \mathrm{HAuCl}_{4}$ in ethanol for 20 minutes. This Au salt is expected to bind only with the pyridine groups of P2VP polymer in the PS-b-P2VP BCPs $[18,28]$. After gold deposition the samples were rinsed with deionized water multiple times in order to remove excess Au salts. Annealing of these $\mathrm{Au}$ precursor infiltrated BCP micelle samples were done using a hot plate inside a nitrogen filled glove box at different temperatures. Once annealing had finished the samples were allowed to cool down to room temperature before being taken to be etched using oxygen plasma (March plasma etcher) for removing all the polymers from the samples to obtain only Au nanoparticles on the silicone substrate's surface.

Characterizations. Both the $\mathrm{BCP}$ nanostructures and Au nanoparticles were imaged using a Field Emission Scanning Electron Microscope (FESEM) by FEI Quanta 200 FEG instrument and analyzed using ImageJ. 


\section{Results and Discussion}

PS $(440,000)-b-P 2 V P(353,000)$ diblock copolymer templates were used to test the effects of annealing temperature and duration time on the fabrication of $\mathrm{Au}$ anisotropic nanoparticles. Figure 3.2 (a-e) shows that by varying the annealing time for $200{ }^{\circ} \mathrm{C}$ we can directly affect both the size and concentration of anisotropic nanoparticles on a substrate. Figure $3.2(\mathrm{f}-\mathrm{j})$ also shows a very similar trend at $350{ }^{\circ} \mathrm{C}$. For these experiments data was obtained from five different annealing times of $0.5 \mathrm{hrs}, 1.0 \mathrm{hrs}, 2.0$ hrs, $4.0 \mathrm{hrs}$ and $8.0 \mathrm{hrs}$ at $200{ }^{\circ} \mathrm{C}$. The data shows a general decrease in average nanoparticle size from approximately 61.9 (2) $\mathrm{nm}$ at $0.5 \mathrm{hrs}$ to 34.4 (4) $\mathrm{nm}$ for $8.0 \mathrm{hrs}$ of annealing. The same sample set also shows a change between the total number of particles on the surface at x 50,000 magnification. Resulting in a count of 122 nanoparticles at $0.5 \mathrm{hrs}$ increasing to 467 nanoparticles for $8 \mathrm{hrs}$ annealing duration time. The same general trend also holds true for an annealing temperature of $350{ }^{\circ} \mathrm{C}$ and the same annealing times ranging from 0.5 to $8 \mathrm{hrs}$. Figure 3.2 (f) shows an approximate mean nanoparticle size of 65.9 (2) $\mathrm{nm}$ for $0.5 \mathrm{hrs}$ annealing time at $350{ }^{\circ} \mathrm{C}$. The annealing times ranging from 1 to $8 \mathrm{hrs}$ (i.e, $1.0 \mathrm{hr}, 2.0 \mathrm{hrs}, 4.0 \mathrm{hrs}$ and $8.0 \mathrm{hrs}$ ) also show a downward trend decreasing to 39.5 (4) $\mathrm{nm}$ at $8.0 \mathrm{hrs}$ annealing time. In addition, a steady increase in the total number of nanoparticles from 125 at $0.5 \mathrm{hrs}$ to 351 particles for 8.0 hrs annealing time, at $350{ }^{\circ} \mathrm{C}$. All data has been placed in Table 3.1 for convenience and ease of viewability. 
Table 3.1: Measured mean particle size and total number of particles counted of SEM images at a magnification of x 50,000.

\begin{tabular}{cccc}
\hline $\begin{array}{c}\text { Annealing } \\
\text { temperature }\end{array}$ & $\begin{array}{c}\text { Annealing } \\
\text { time (hrs) }\end{array}$ & $\begin{array}{c}\text { Mean particle } \\
\text { size (nm) }\end{array}$ & $\begin{array}{c}\text { Total number of } \\
\text { distinguishable particles }\end{array}$ \\
\hline $200{ }^{\circ} \mathrm{C}$ & 0.5 & 61.938 & 122 \\
& 1.0 & 61.876 & 128 \\
& 2.0 & 67.731 & 120 \\
& 4.0 & 57.713 & 181 \\
& 8.0 & 34.376 & 467 \\
\hline \multirow{2}{*}{$350^{\circ} \mathrm{C}$} & 0.5 & 65.874 & 125 \\
& 1.0 & 60.456 & 149 \\
& 2.0 & 55.031 & 180 \\
& 4.0 & 51.517 & 201 \\
& 8.0 & 39.549 & 351 \\
\hline
\end{tabular}

Table 3.1 has been plotted in Figure 3.1 to show the general trend of both the mean particle size and the total number of distinguishable particles at both $200{ }^{\circ} \mathrm{C}$ and $350{ }^{\circ} \mathrm{C}$ for a varied time scale ranging from 0.5 to 8.0 hours. This data has also been plotted in Figure 3.1 for a visual representation of the rate of changes of both the mean particle size and the total number of distinguishable particles. From Figure $3.1(\mathrm{a}, \mathrm{c})$ we can see that the mean particle size decreases as the total number of distinguishable particles increase drastically. A possible explanation for this effect will be discussed in conjunction with Figure 3.2 to more easily show the related distribution transition of particles through time. 


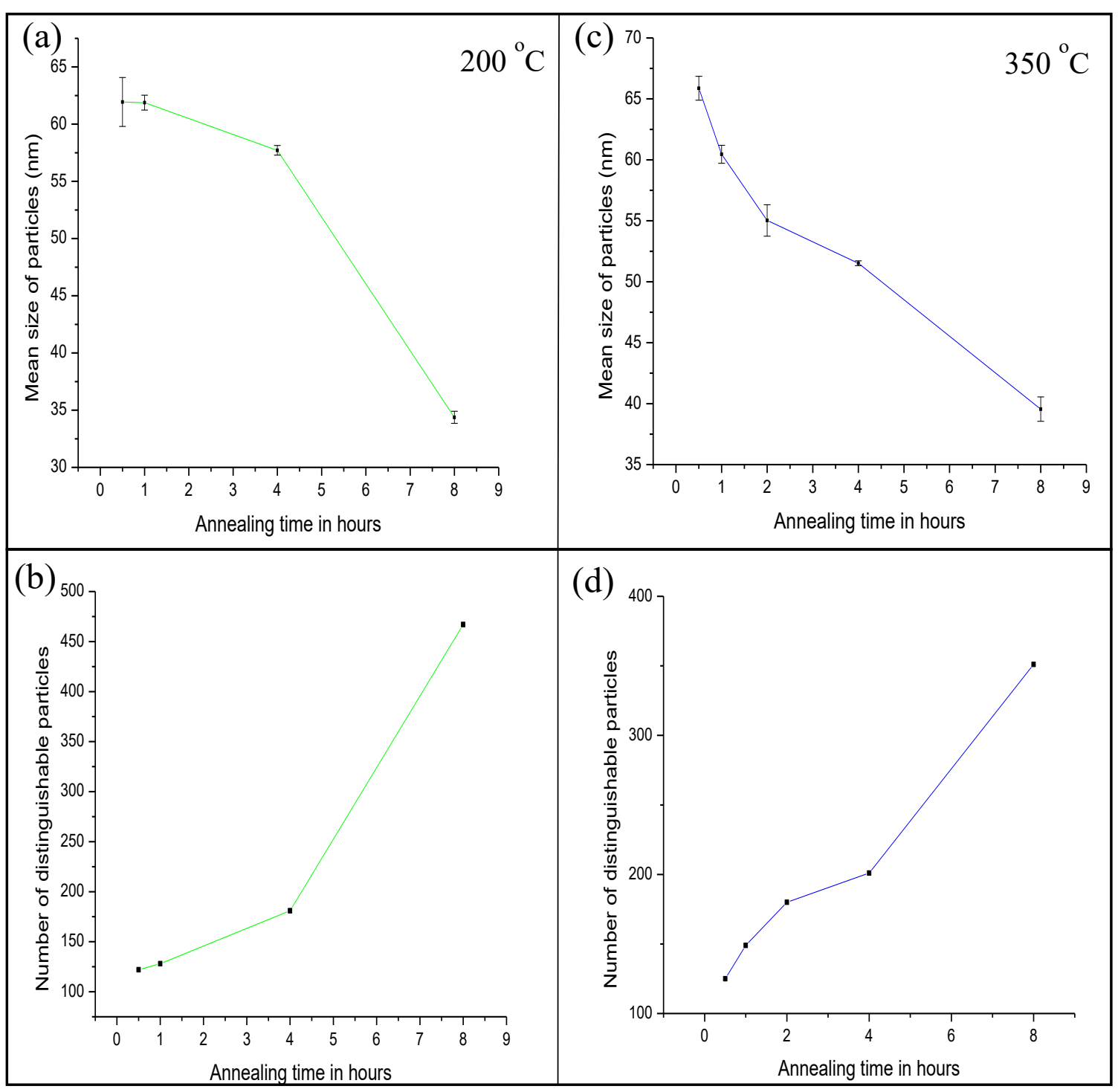

Figure 3.1: (a-b) Data plots at $200{ }^{\circ} \mathrm{C}$ for both mean particle size and total number of distinguishable particles versus annealing time. (c-d) The same type of data is plotted but instead at $350{ }^{\circ} \mathrm{C}$. 


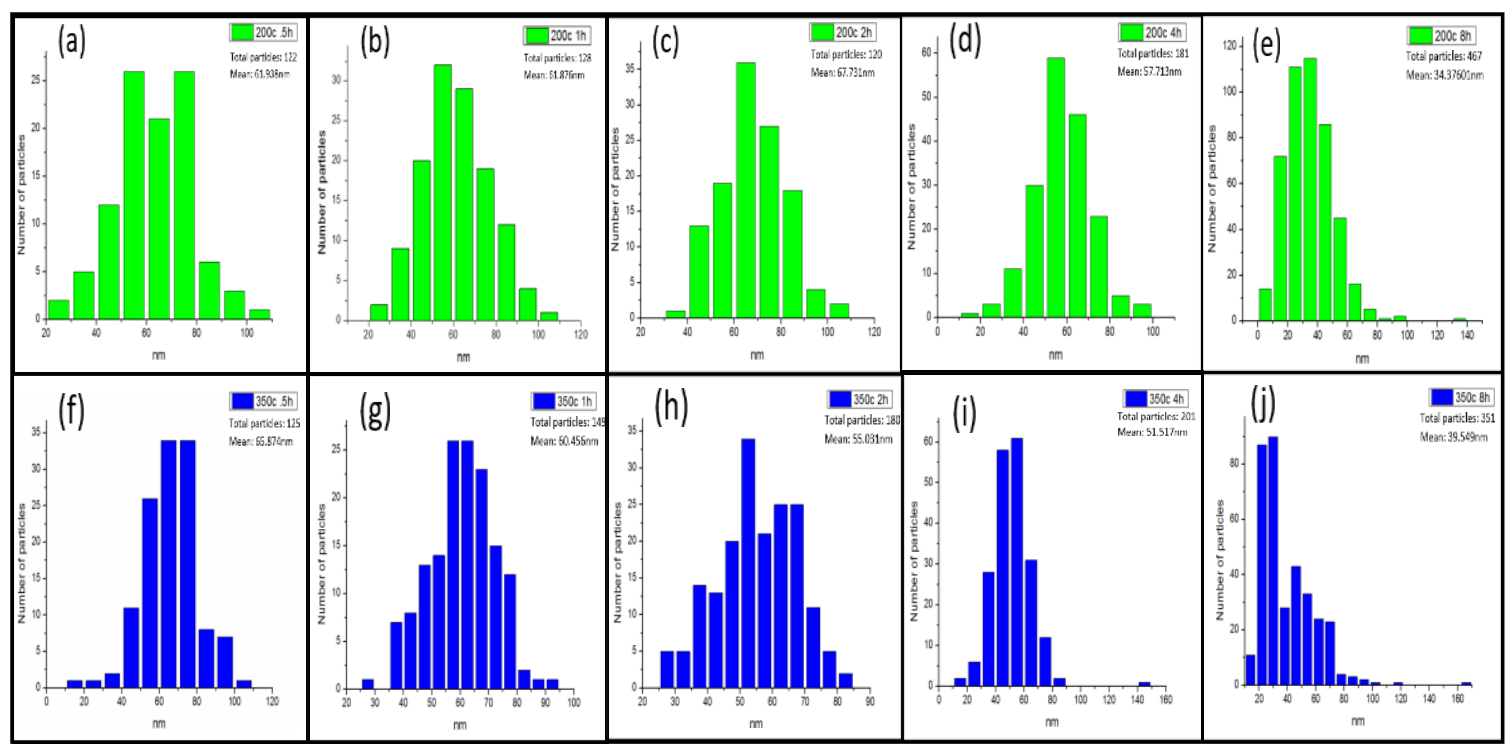

Figure 3.2: (a-j) Measured nanoparticle size of all individual Au nanoparticles at a magnification of $x 50,000$ of SEM images. (a-e) Histogram plots of samples that were annealed at $200{ }^{\circ} \mathrm{C}$ with varied annealing of $0.5 \mathrm{hr}$ (a), $1.0 \mathrm{hr}$ (b), $2.0 \mathrm{hrs}$ (c), $4.0 \mathrm{hrs}$ (d), and $8.0 \mathrm{hrs}(\mathrm{e})$. (f-j) Histogram plots of samples annealed at $350{ }^{\circ} \mathrm{C}$ for $0.5 \mathrm{hr}$ (f), $1.0 \mathrm{hr}(\mathrm{g}), 2.0 \mathrm{hrs}(\mathrm{h}), 4.0 \mathrm{hrs}(\mathrm{i})$ and $8.0 \mathrm{hrs} \mathrm{(j)}$.

The data described above and shown in Figure 3.2 exhibit a consistent trend excluding for the case of annealing for $4.0 \mathrm{hrs}$ at $200{ }^{\circ} \mathrm{C}$. Figure 3.2 (c) shows a reduction of 8 nanoparticles and a $6.0(10) \mathrm{nm}$ increase in the mean nanoparticle size for this case. We suspect that this variance in the sample stems from the formation of larger than average P2VP micelles; this in effect allowed more gold to migrate into its core during gold deposition, resulting in slightly larger anisotropic nanoparticles after annealing. The histograms shown in Figure 3.2 (a-c) exhibit negligible change both in total count and mean particle size at $200{ }^{\circ} \mathrm{C}$ until annealing time surpasses 2 hours. This might be explained by the glass transition temperatures of both PS and P2VP $\mathrm{VP}^{56}\left(\mathrm{~T}_{\mathrm{g}} \sim 100{ }^{\circ} \mathrm{C}\right) . \mathrm{In}$ both cases the polymer chains are more kinetically active resulting in the formation of polymer melts at both $200{ }^{\circ} \mathrm{C}$ and $350{ }^{\circ} \mathrm{C}$. Through this process the polymer melt allows 
the migration of P2VP micelles containing Au nanoparticles into larger localized droplets of the minority P2VP within the majority matrix of molten PS. This would explain how smaller indiscernible particles are capable of coalescing, resulting in the formation of larger nanoparticles. In comparison with $350{ }^{\circ} \mathrm{C}$ the rate of migration is much slower at $200{ }^{\circ} \mathrm{C}$ which would account for the increase in time required before smaller nanoparticles coalesced into a size viewable by SEM.

In addition to what was previously discussed; Figure 3.2 also shows the start of a binomial distribution. If we take a look at the histograms associated with $350{ }^{\circ} \mathrm{C}$ in Figure 3.2 (f-j) it is easier to see this binomial distribution which appears to be taking the form of competing processes between the reduction of mean particle size and the increase in total count of distinguishable nanoparticles. Initially this binomial distribution is not very apparent between .5 and the 2 hours mark but starts to show up between 4 and 8 hours by which time most of the small particulates have already formed larger distinguishable measurable particles and therefore resulting in a decrease in the of rate increase of the total nanoparticle count. In addition to this in Figure 3.2 (i-j) we can now see the point in which our starting particles of 50-70 nm's are now coalescing into very large nanoparticles of 140-170 nm's in size. So now, not only is this increasing the average size of these nanoparticles; but it is also decreasing the total number of particles on the substrate. So, in short this implies that at higher temperatures and longer annealing times this type of distribution will become prevalent. 


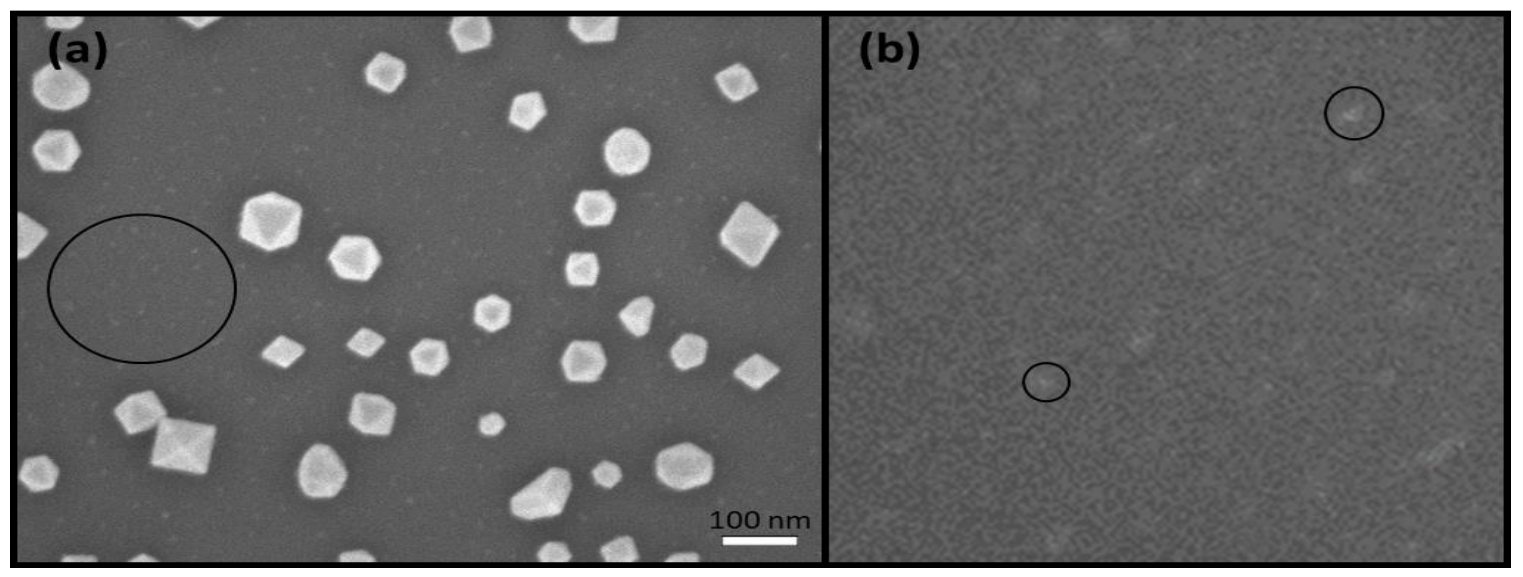

Figure 3.3: (a) SEM image of plasma etched sample annealed at $200{ }^{\circ} \mathrm{C}$ for 2 hrs. (b) Zoomed image of (a).

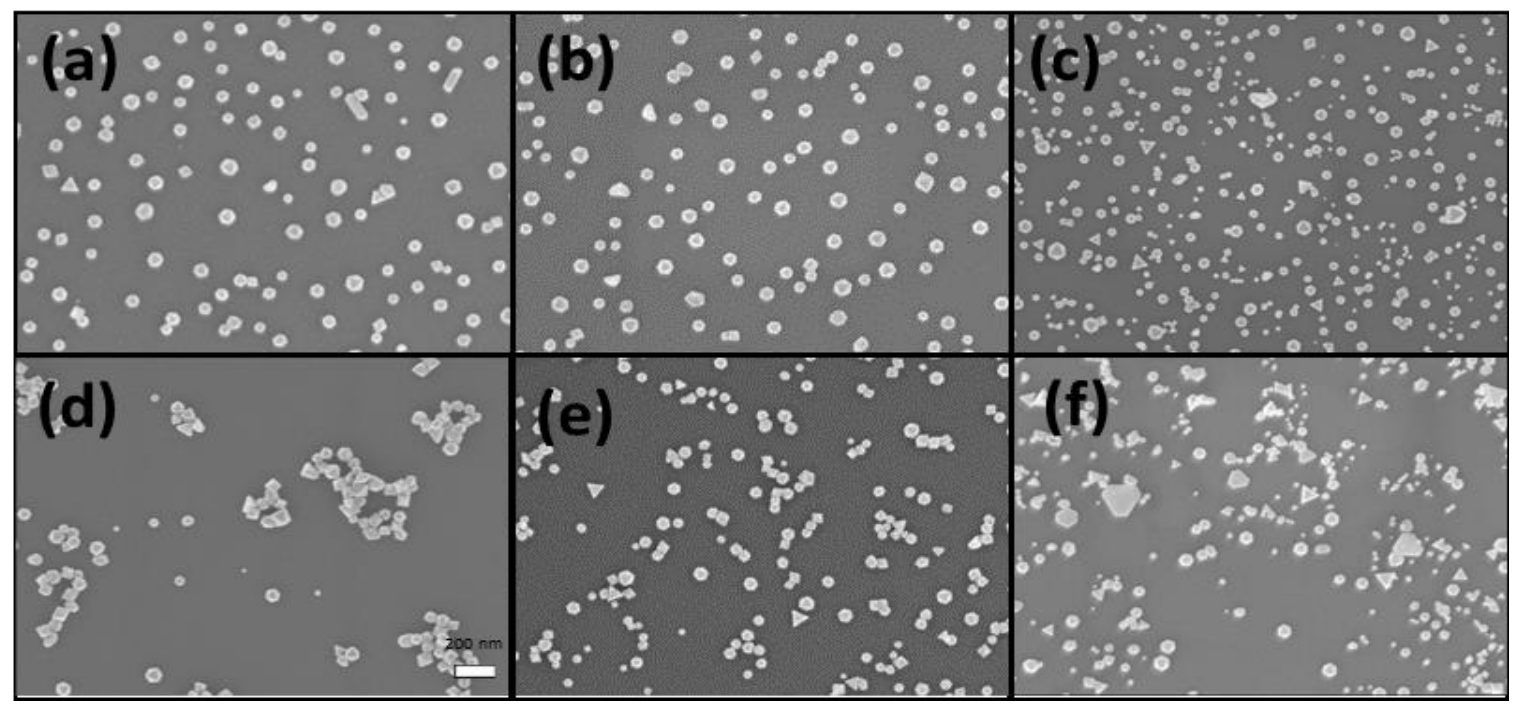

Figure 3.4: (a-c) SEM images of samples annealed at $200{ }^{\circ} \mathrm{C}$ for $.5 \mathrm{hr}$ (a), $2 \mathrm{hrs}$ (b) and $8 \mathrm{hrs}(\mathrm{c})$. (d-f) SEM images taken of $350{ }^{\circ} \mathrm{C}$ samples at .5hr (d), $2 \mathrm{hrs}(\mathrm{e})$ and 8 hrs (f). All images measures with ImageJ at an SEM magnification of x 50,000.

As demonstrated by Figure 3.3 the presences of small Au particulates along the surface clearly shows that $200{ }^{\circ} \mathrm{C}$ for 2 hours was inefficient time for the particulates to coalesce into larger particles which coincides with data from Figure 3.2.

Figure 3.4 depicts a majority morphology of octahedron nanoparticles with an increase of other geometric shapes (i.e. truncated pyramidal, hexagonal, etc.) through the 
transition over time by which these anisotropic particles coalesced and grew. This phenomenon is even more profound when both the annealing time and temperature are increased to $350{ }^{\circ} \mathrm{C}$ for 8 hours as illustrated by Figure 3.4 (f). Through this we were able to observe the nonoptimal conditions that lead to the formation of very large nanoparticles alongside their smaller aggregated counterparts. What this shows is by what means optimal conditions can be chosen to fine tune not only the nanoparticle size but also the total number of nanoparticles.

\section{Conclusions}

In this study we report an analysis of analytical data that can be used in the control and growth of Au anisotropic nanostructures through the use of a PS-b-P2VP micellar template. We were able to show that by simply changing annealing parameters, namely annealing time or temperature, it is possible to affect the average size and total number of resultant nanoparticles grown on a substrate. I hypothesize that the mechanism responsible for this process is related to the glass temperature of both PS and P2VP by which a polymer melt is formed at annealing temperatures greater than $\left(\mathrm{T}_{\mathrm{g}} \sim 100{ }^{\circ} \mathrm{C}\right)$. This in turn, allowed the migration of Au filled P2VP micelles into larger localized droplets. Subsequently, smaller indiscernible particles are now grouped in close proximity resulting in nucleation. This allows the size manipulation of nanoparticles through simple parameters such as annealing temperature and time. Through this research we can also extrapolate by what means to maximize the growth of nanoparticles between a given size distribution while also minimizing the nucleation of nanoparticles above this desired distribution. 


\section{References}

[1] Antonietti, M.; Foerster, S.; Hartmann, J.; Oestreich, S. Macromolecules 1996, 29, 3800.

[2] Cheng, J. Y.; Ross, C. A.; Smith, H. I.; Thomas, E. L. AdV. Mater. 2006, 18, 2505.

[3] Malenfant, P. R. L.; Wan, J.; Taylor, S. T.; Manoharan, M. Nature Nanotechnol. 2007, 2, 43.

[4] Balsara, N. P.; Hahn, H. Chem. Nanostruct. Mater. 2003, 317.

[5] Hamley, I. W. Angew. Chem., Int. Ed. 2003, 42, 1692.

[6] Ruzette, A.-V.; Leibler, L. Nature Mater. 2005, 4, 19.

[7] Gwyn, C. W.; Stulen, R.; Sweeney, D.; Attwood, D. J. Vac. Sci. Technol. B 1998, 16,3142 .

[8] Aizpurua, J., Hanarp, P., Sutherland, D. S., Käll, M., Bryant, G. W., \& De Abajo, F. G. (2003). Optical properties of gold nanorings. Physical Review Letters, 90(5), 057401 .

[9] Yang, S. M., Jang, S. G., Choi, D. G., Kim, S., \& Yu, H. K. (2006). Nanomachining by colloidal lithography. small, 2(4), 458-475.

[10] Liusman, C., Li, S., Chen, X., Wei, W., Zhang, H., Schatz, G. C., ... \& Mirkin, C. A. (2010). Free-standing bimetallic nanorings and nanoring arrays made by on-wire lithography. ACS nano, 4(12), 7676-7682.

[11] Bruinink, C. M., Péter, M., Maury, P. A., De Boer, M., Kuipers, L., Huskens, J., \& Reinhoudt, D. N. (2006). Capillary force lithography: fabrication of functional polymer templates as versatile tools for nanolithography. Advanced Functional Materials, 16(12), 1555-1565.

[12] N. R. Jana, L. Gearheart, C. J. Murphy, J. Phys. Chem. B 2001, 105, 4065.

[13] R. C. Jin, Y. C. Cao, E. C. Hao, G. S. Metraux, G. C. Schatz, C. A. Mirkin, Nature 2003, 425, 487.

[14] Y. G. Sun, B. Gates, B. Mayers, Y. N. Xia, Nano Lett. 2002, 2, 165.

[15] S. H. Im, Y. T. Lee, B. Wiley, Y. N. Xia, Angew. Chem. Int. Ed. 2005, 44, 2154.

[16] Jain, P. K.; Lee, K. S.; El-Sayed, I. H.; El-Sayed, M. A., Calculated Absorption and Scattering Properties of Gold Nanoparticles of Different Size, Shape, and Composition: Applications in Biological Imaging and Biomedicine. The Journal of Physical Chemistry B 2006, 110 (14), 7238-7248.

[17] Anker, J. N.; Hall, W. P.; Lyandres, O.; Shah, N. C.; Zhao, J.; Van Duyne, R. P., Biosensing with plasmonic nanosensors. Nature Materials 2008, 7, 442.

[18] Sperling, R. A.; Rivera Gil, P.; Zhang, F.; Zanella, M.; Parak, W. J., Biological applications of gold nanoparticles. Chemical Society Reviews 2008, 37 (9), 18961908.

[19] Huang, X.; El-Sayed, I. H.; Qian, W.; El-Sayed, M. A., Cancer Cell Imaging and Photothermal Therapy in the Near-Infrared Region by Using Gold Nanorods.

Journal of the American Chemical Society 2006, 128 (6), 2115-2120.

[20] Zijlstra, P.; Chon, J. W. M.; Gu, M., Five-dimensional optical recording mediated by surface plasmons in gold nanorods. Nature 2009, 459, 410.

[21] Pan, H.; Chen, W.; Feng, Y. P.; Ji, W.; Lin, J., Optical limiting properties of metal nanowires. Applied Physics Letters 2006, 88 (22), 223106. 
[22] Sau, T. K.; Rogach, A. L.; Jäckel, F.; Klar, T. A.; Feldmann, J., Properties and Applications of Colloidal Nonspherical Noble Metal Nanoparticles. Advanced Materials 2010, 22 (16), 1805-1825.

[23] Tian, N.; Zhou, Z.-Y.; Sun, S.-G.; Ding, Y.; Wang, Z. L., Synthesis of Tetrahexahedral Platinum Nanocrystals with High-Index Facets and High ElectroOxidation Activity. Science 2007, 316 (5825), 732-735.

[24] Jang, N. H.; Suh, J. S.; Moskovits, M., Photochemical Desorption of 4Vinylbenzoic Acid Adsorbed on Silver Colloid Surfaces. The Journal of Physical Chemistry B 1997, 101 (9), 1649-1654.

[25] Yin, Y.; Erdonmez, C.; Aloni, S.; Alivisatos, A. P., Faceting of Nanocrystals during Chemical Transformation: From Solid Silver Spheres to Hollow Gold Octahedra. Journal of the American Chemical Society 2006, 128 (39), 12671-12673.

[26] Hao, F.; Nehl, C. L.; Hafner, J. H.; Nordlander, P., Plasmon Resonances of a Gold Nanostar. Nano Letters 2007, 7 (3), 729-732.

[27] Kreibig, U.; Vollmer, M., Optical Properties of Metal Clusters. Springer: 1995.

[28] Kelly, K. L.; Coronado, E.; Zhao, L. L.; Schatz, G. C., The Optical Properties of Metal Nanoparticles: The Influence of Size, Shape, and Dielectric Environment. The Journal of Physical Chemistry B 2003, 107 (3), 668-677. 


\section{CHAPTER 4: SUMMARY}

In conclusion, a simple fabrication method by which Au anisotropic nanoparticles can be patterned with PS-b-P2VP micelles template has been described. Furthermore, it was shown that Au nanoparticles of various geometrical shapes, namely octahedral, icosahedral, and triangular prism can be formed at a relatively low temperature of heat treatment. This study also investigated the extinction spectroscopy of anisotropic $\mathrm{Au}$ nanoparticles which showed two LSPR peaks in the visible range (center $\sim 650 \mathrm{~nm}$ ), and the other in the NIR range (center $\sim 875 \mathrm{~nm}$ ).

In the second part of my study, the focus has been geared toward the investigation of the effects of thermal annealing parameters (i.e. annealing time and temperature) in a nitrogen atmosphere for the fabrication of anisotropic nanoparticles. I was able to show that by changing annealing parameters it is possible to affect the average size of nanoparticles on a substrate by coalescing smaller sized Au nanoparticles. From these results, it should be possible to extrapolate by what means it may be possible to maximize the growth of particles between a given range and minimize the growth of nanoparticles above this range. 


\section{CHAPTER 5: REFERENCES FOR INTRODUCTION}

[1] Wei, Y., Li, B., Han, Y., \& Pan, C. (2008). Ring-shaped morphology in H-shaped block copolymer thin films. Soft Matter, 4(12), 2507-2512.

[2] Matsen, M. W., \& Bates, F. S. (1996). Unifying weak-and strong-segregation block copolymer theories. Macromolecules, 29(4), 1091-1098.

[3] Knoll, A., Horvat, A., Lyakhova, K. S., Krausch, G., Sevink, G. J. A., Zvelindovsky, A. V., \& Magerle, R. (2002). Phase behavior in thin films of cylinder-forming block copolymers. Physical Review Letters, 89(3), 035501.

[4] Elbs, H., Drummer, C., Abetz, V., \& Krausch, G. (2002). Thin film morphologies of ABC triblock copolymers prepared from solution. Macromolecules, 35(14), 55705577.

[5] Tang, W. H., \& Witten, T. A. (1998). Quenched degrees of freedom in symmetric diblock copolymer thin films. Macromolecules, 31(9), 3130-3135.

[6] Russel, T. P., Menelle, A., Anastasiadis, S. H., Satija, S. K., \& Majkrzak, C. F. (1991). Unconventional morphologies of symmetric, diblock copolymers due to film thickness constraints. Macromolecules, 24(23), 6263-6269.

[7] Kim, G., \& Libera, M. (1998). Morphological Development in Solvent-Cast Polystyrene- Polybutadiene- Polystyrene (SBS) Triblock Copolymer Thin Films. Macromolecules, 31(8), 2569-2577.

[8] Temple, K., Kulbaba, K., Power-Billard, K. N., Manners, I., Leach, K. A., Xu, T., ... \& Hawker, C. J. (2003). Spontaneous Vertical Ordering and Pyrolytic Formation of Nanoscopic Ceramic Patterns from Poly (styrene-bferrocenylsilane). Advanced Materials, 15(4), 297-300.

[9] Ross, C. A. (2001). Patterned magnetic recording media. Annual Review of Materials Research, 31(1), 203-235.

[10] Fan, H. J., Werner, P., \& Zacharias, M. (2006). Semiconductor nanowires: from self-organization to patterned growth. Small, 2(6), 700-717.

[11] Haryono, A., \& Binder, W. H. (2006). Controlled Arrangement of Nanoparticle Arrays in Block-Copolymer Domains. Small, 2(5), 600-611.

[12] Ye, J., 叶坚, Shioi, M., Lodewijks, K., Lagae, L., Kawamura, T., \& Van Dorpe, P. (2010). Tuning plasmonic interaction between gold nanorings and a gold film for surface enhanced Raman scattering. Applied physics letters, 97(16), 163106.

[13] Baek, I. C., Vithal, M., Chang, J. A., Yum, J. H., Nazeeruddin, M. K., Grätzel, M., ... \& Seok, S. I. (2009). Facile preparation of large aspect ratio ellipsoidal anatase TiO 2 nanoparticles and their application to dye-sensitized solar cell. Electrochemistry Communications, 11(4), 909-912.

[14] Haque, S. A., Koops, S., Tokmoldin, N., Durrant, J. R., Huang, J., Bradley, D. D., \& Palomares, E. (2007). A Multilayered Polymer Light-Emitting Diode Using a Nanocrystalline Metal-Oxide Film as a Charge-Injection Electrode. Advanced Materials, 19(5), 683-687.

[15] Aizpurua, J., Hanarp, P., Sutherland, D. S., Käll, M., Bryant, G. W., \& De Abajo, F. G. (2003). Optical properties of gold nanorings. Physical Review Letters, 90(5), 057401 . 
[16] Liusman, C., Li, S., Chen, X., Wei, W., Zhang, H., Schatz, G. C., ... \& Mirkin, C. A. (2010). Free-standing bimetallic nanorings and nanoring arrays made by on-wire lithography. ACS nano, 4(12), 7676-7682.

[17] Bruinink, C. M., Péter, M., Maury, P. A., De Boer, M., Kuipers, L., Huskens, J., \& Reinhoudt, D. N. (2006). Capillary force lithography: fabrication of functional polymer templates as versatile tools for nanolithography. Advanced Functional Materials, 16(12), 1555-1565.

[18] Yang, S. M., Jang, S. G., Choi, D. G., Kim, S., \& Yu, H. K. (2006). Nanomachining by colloidal lithography. small, 2(4), 458-475.

[19] Cho, H., Choi, S., Kim, J. Y., \& Park, S. (2011). Fabrication of gold dot, ring, and corpuscle arrays from block copolymer templates via a simple modification of surface energy. Nanoscale, 3(12), 5007-5012.

[20] Hawker, C. J., \& Russell, T. P. (2005). Block copolymer lithography: Merging "bottom-up" with "top-down" processes. MRS bulletin, 30(12), 952-966.

[21] Förster, S., \& Antonietti, M. (1998). Amphiphilic block copolymers in structurecontrolled nanomaterial hybrids. Advanced Materials, 10(3), 195-217.

[22] BATES, F. (1991). Polymer-polymer phase behavior. Science, 251(4996), 898-905.

[23] Shalaev, V. M., \& Kawata, S. (2007). Advances in Nano-optics and nano-photonics.

[24] Mody, V. V., Siwale, R., Singh, A., \& Mody, H. R. (2010). Introduction to metallic nanoparticles. Journal of Pharmacy and Bioallied Sciences, 2(4), 282-289. http://doi.org/10.4103/0975-7406.72127

[25] McNaught, A. D., \& McNaught, A. D. (1997). Compendium of chemical terminology (Vol. 1669). Oxford: Blackwell Science.

[26] Pasquali, M. (2010). Gelation: Grow with the flow. Nature materials, 9(5), 381-382. 